NBER WORKING PAPER SERIES

\title{
SOCIAL SECURITY EXPECTATIONS AND RETIREMENT SAVINGS DECISIONS
}

\author{
Jeff Dominitz \\ Charles F. Manski \\ Jordan Heinz \\ Working Paper 8718 \\ http://www.nber.org/papers/w8718
NATIONAL BUREAU OF ECONOMIC RESEARCH
1050 Massachusetts Avenue
Cambridge, MA 02138
January 2002

This research was supported in part by National Institute on Aging Grant 2 P01 AG10179-04A1 and National Science Foundation grant SES-0001436. We are grateful to the University of Wisconsin Survey Center for enabling collection of the telephone survey data and to Jora Stixrud for assistance in performance of the faceto-face survey. We have benefited from the comments of participants in seminars at the Hebrew University of Jerusalem, Northwestern University, and the University of Pennsylvania; participants in the TMR Savings and Pensions Workshop held August 2001 in Evian, France; and participants in the Conference on Survey Research on Household Expectations and Preferences held November 2001 in Ann Arbor, Michigan. The views expressed herein are those of the authors and not necessarily those of the National Bureau of Economic Research.

(C) 2002 by Jeff Dominitz, Charles F. Manski and Jordan Heinz. All rights reserved. Short sections of text, not to exceed two paragraphs, may be quoted without explicit permission provided that full credit, including (C) notice, is given to the source. 
Social Security Expectations and Retirement Savings Decisions

Jeff Dominitz, Charles F. Manski and Jordan Heinz

NBER Working Paper No. 8718

January 2002

JEL No. H55, D84, E2

\begin{abstract}
Retirement savings decisions should depend on expectations of Social Security retirement income. Persons may be uncertain of their future Social Security benefits for several reasons, including uncertainty about their future labor earnings, the formula now determining social security benefits, and the future structure of the Social Security system. To learn how Americans perceive their benefits, we have elicited Social Security expectations from respondents to the Survey of Economic Expectations. We have also performed a more intensive face-to-face survey on a small sample of respondents. This paper presents the empirical findings. It also illustrates how data on expectations may help predict how Social Security policy affects retirement savings.
\end{abstract}

\title{
Jeff Dominitz
}

H. John Heinz III School of Public Policy and Management, Carnegie Mellon University, 5000 Forbes Avenue, Pittsburgh, PA 15213 dominitz@andrew.cmu.edu

Charles F. Manski

Department of Economics and Institute for Policy Research, Northwestern University, 2003 Sheridan Road, Evanston, IL 60208 and NBER

cfmanski@northwestern.edu

Jordan Heinz

Department of Economics and School of Education and Social Policy, Northwestern University, 2003 Sheridan Road, Evanston, IL 60208 jheinz@northwestern.edu 


\section{$\underline{1 . \text { Introduction }}$}

Retirement savings decisions in the United States should depend on expectations of Social Security retirement income. Persons may be uncertain of their future Social Security benefits for several reasons, including uncertainty about their future labor earnings, the formula now determining social security benefits, and the future structure of the Social Security system. Structural uncertainty is particularly pertinent today, as Congress and the President contemplate possibly radical revision of a Social Security system declared by President Bush's Commission to Strengthen Social Security to have "reached retirement age."1 Some proposed revisions, notably those calling for private investment of OASDI taxes, could increase uncertainty about future benefits. Other proposals, notably those calling for the government to create a "Social Security lockbox" of guaranteed benefits, could reduce uncertainty. The Social Security Administration (SSA) calls the public's attention to the possibility of future change in its document The Future of Social Security, which begins: "Will Social Security be there for you? Absolutely. The only real question is what kind of Social Security system we will have."2

Although uncertainty about Social Security benefits should be widespread, there is reason to think that the degree and nature of this uncertainty varies systematically across the population. Under the existing formula with a benefit cap, older workers with histories of consistently high levels of earnings should face less uncertainty about their benefits levels than do those with

\footnotetext{
1 Richard W. Stevenson, New York Times, July 20, 2001.

${ }^{2}$ Social Security Administration Publication No. 05-10055, August 2000. http://www.ssa.gov/pubs/10055.html
} 
histories of fluctuating earnings. ${ }^{3}$ Younger workers should face more labor earnings uncertainty than older workers, and also more uncertainty about the future structure of the system.

Research aiming to understand the impact of Social Security policy on retirement savings decisions has been hampered by a dearth of empirical evidence on Social Security expectations. Respondents to the Retirement History Survey and to the Health and Retirement Study have provided point forecasts of their future benefits (see Bernheim, 1988; Gustman and Steinmeier, 1999, 2001). However, respondents' uncertainty about their benefits has not been measured. Nor have attempts been made to learn the process by which persons form their expectations.

Beginning in 1999, we have elicited probabilistic expectations of Social Security retirement benefits from respondents to our national Survey of Economic Expectations (SEE), which has been ongoing since 1993 (see Dominitz and Manski, 1997a, 1997b). Moreover, in the summer of 2001, we performed a more intensive face-to-face survey on a small sample of respondents. This paper presents the empirical findings.

To frame the relevant issues in a simple yet rigorous manner, Section 2 poses an idealized model of retirement savings. Section 3 describes the data on Social Security expectations that we have collected in the SEE and in the face-to-face survey. Section 4 reports our findings. Section 5 uses the decision model of Section 2 and the empirical findings of Section 4 to simulate how Social Security policy may affect retirement savings. Section 6 draws conclusions.

\footnotetext{
${ }^{3}$ Expectations of benefits under the existing Social Security system may be influenced by the annual statements that workers now receive from the Social Security Administration. Beginning in October 1999, SSA has mailed workers of age 25 and older annual point estimates of their prospective benefits. Previously, a Personal Earnings and Benefit Estimate Statement had been available on request since 1988. See Section 4.2 for further discussion.
} 


\section{A Simple Model of Retirement Savings}

\section{Optimal Savings Decisions in a Two-Period World}

An idealized two-period model makes evident the role of Social Security expectations as a determinant of retirement savings. Suppose that a person lives for two periods, working in the first period and retiring in the second. In the first period, the person receives labor earnings and other income $Y_{1}>0$, which he must allocate between consumption and retirement savings. Savings may be invested in part in a mutual fund, with uncertain real rate of return, and in part in a risk-free asset. Let $S^{m} \geq 0$ denote savings in the mutual fund and $S^{f} \geq 0$ denote risk-free savings. In the second period, the person consumes his Social Security retirement benefit $Y_{2} \geq 0$ and realized savings $\left(1+\mathrm{r}^{\mathrm{m}}\right) \mathrm{S}^{\mathrm{m}}+\left(1+\mathrm{r}^{\mathrm{f}}\right) \mathrm{S}^{\mathrm{f}}$, where $\mathrm{r}^{\mathrm{m}}$ is the realized rate of return on the mutual fund and $\mathrm{r}^{\mathrm{f}}$ is the risk-free rate of return. Thus, consumption in the two periods must satisfy the budget constraints

$$
\begin{aligned}
& \mathrm{C}_{1}=\mathrm{Y}_{1}-\mathrm{S}^{\mathrm{m}}-\mathrm{S}^{\mathrm{f}} \\
& \mathrm{C}_{2}=\mathrm{Y}_{2}+\left(1+\mathrm{r}^{\mathrm{m}}\right) \mathrm{S}^{\mathrm{m}}+\left(1+\mathrm{r}^{\mathrm{f}}\right) \mathrm{S}^{\mathrm{f}} .
\end{aligned}
$$

The utility associated with consumption of the bundle $\left(C_{1}, C_{2}\right)$ is $U\left(C_{1}\right)+\beta U\left(C_{2}\right)$, where $\beta$ is the discount rate.

Suppose that, when facing the consumption-savings decision in the first period, the person knows his contemporaneous income $\mathrm{Y}_{1}$, but does not know either his future Social Security benefit $Y_{2}$ or the return $r^{m}$ on the mutual fund. Suppose that he forms a subjective 
distribution $\mathrm{P}\left(\mathrm{Y}_{2}, \mathrm{r}^{\mathrm{m}}\right)$ and acts to maximize expected utility. Then, in the first period, the person chooses retirement savings to solve the problem

$$
\max _{S^{m}, S^{f}} U\left(Y_{1}-S^{m}-S^{f}\right)+\beta \int U\left(Y_{2}+\left(1+r^{m}\right) S^{m}+\left(1+r^{f}\right) S^{f}\right) d P\left(Y_{2}, r^{m}\right)
$$

Thus, a person's retirement savings decision depends on his first-period income $\mathrm{Y}_{1}$, his preferences $[\mathrm{U}(),. \beta]$, and his expectations $\mathrm{P}\left(\mathrm{Y}_{2}, \mathrm{r}^{\mathrm{m}}\right)$ of Social Security benefits and mutual fund returns.

\section{Social Security Policy and Expectations}

In the context of this model, social security policy affects the retirement savings decision by influencing the person's expectations. Policy changes could easily affect the joint distribution $\mathrm{P}\left(\mathrm{Y}_{2}, \mathrm{r}^{\mathrm{m}}\right)$, but it is perhaps easiest to speculate on the changes to the marginal distribution $\mathrm{P}\left(\mathrm{Y}_{2}\right)$.

Consider creation of a "Social Security Lockbox" that guarantees future benefits to persons now working. Such a guarantee would presumably reduce the size of the left tail of $\mathrm{P}\left(\mathrm{Y}_{2}\right)$, as workers are relieved of the present-day concern with a catastrophic collapse of the Social Security system. However, the specific effect of the policy change on expectations would likely depend on the nature of the government guarantee. A government commitment to maintain present benefit levels may well have different effects on expectations than would a guarantee of some minimum benefit level.

Revision of the Social Security system to include private investment of a portion of OASDI taxes in a personal retirement account would change Social Security from a system of 
defined benefits to one with a defined-contribution component. When considering private pensions, it is commonly thought that such a change should increase the dispersion of benefit expectations and move their central tendency rightward. However, the effect on Social Security expectations may well depend on the specific form of the private-investment component and on other considerations. For example, Merton (1983) notes that a system combining defined benefits and defined contributions may yield a smaller total risk than a system of defined benefits alone or one of defined contributions alone. Feldstein and Liebman (2001) cite diversification as a leading argument offered by advocates of a mixed system.

The Need for Empirical Evidence on Expectations

A recent NBER volume on the risk aspects of investment-based Social Security reforms (Campbell and Feldstein, 2001) highlights the role of benefit expectations. Yet this volume contains no direct empirical evidence on these expectations. McHale (2001) attempts to infer the "political risks" of defined benefit systems from international evidence on changes in benefit rules. Campbell et al. (2001) connect defined-benefit uncertainty to labor income uncertainty through the Social Security benefit formula. Feldstein et al. (2001) suppose that defined benefits are known with certainty and use historical data on the performance of a diversified portfolio of securities to assess the financial risks of an investment-based system.

In the absence of empirical evidence, one can only speculate about how changes in Social Security policy would affect expectations, and thence retirement savings. A natural first step in assembling the necessary empirical evidence is to learn the expectations that Americans presently hold for Social Security benefits. This is the purpose of the surveys described in Section 3. 


\section{Eliciting Expectations of Social Security Benefits}

\subsection{The Survey of Economic Expectations}

The Survey of Economic Expectations, a periodic module in a continuous national telephone survey conducted by the University of Wisconsin Survey Center, was begun in 1993 and has been ongoing since then. Dominitz and Manski (1997a, 1997b), Dominitz (1998, 2001), and Manski and Straub (2000) describe the survey design and report findings on expectations of income, job loss, and other outcomes one year into the future.

Beginning in 1999, the survey has included a series of questions eliciting expectations of Social Security benefits from persons of ages $18-69$. This part of the survey begins with a brief description of the Social Security program and a request for the respondent to predict his eligibility for benefits when he is 70 years old, as follows: ${ }^{4}$

Politicians and the news media have been talking recently about the future of the Social Security retirement system, the federal program providing benefits to retired workers. The amount of benefits for which someone is eligible is currently determined by the person's retirement age and by earnings prior to retirement. There has been much discussion of changing the form of the Social Security system, so the future shape of the system is not certain.

\footnotetext{
${ }^{4}$ These introductory instructions are intended to stimulate the respondent to consider the range of possible outcomes. It is possible that the instructions convey information that respondents use to form expectations. Assessment of such effects based on systematic experimentation with alternative sets of instructions is a worthy subject for future research.
} 
With this in mind, I would like you to think about what kind of Social Security retirement benefits will be available when you are older. In particular, think ahead to when you are about to turn 70 years old and suppose that you are not working at that time.

What is the PERCENT CHANCE that you will be eligible to collect any Social Security retirement benefits at that time?

Respondents who report a positive probability are then asked a series of questions designed to elicit their subjective distribution of benefits, conditional on eligibility. This series follows the format of the income-expectations questions that have been asked in SEE since its inception (see Dominitz and Manski, 1997a). That is, respondents are first asked to report the lowest and highest possible levels of their future benefits. The responses are then used to set thresholds for up to six probabilistic questions about the level of benefits. The series has this form: 5

Suppose you are eligible to collect Social Security benefits when you turn 70. Please think about how much money you would be eligible to collect EACH YEAR. When considering the dollar value, please ignore the effects of inflation or cost-of-living increases. That is, please respond as if a dollar today is worth the same as a dollar when you turn 70 .

What do you think is the LOWEST amount of social security benefits, per year, that you would be eligible to receive?

What do you think is the HIGHEST amount of social security benefits, per year, that you would be eligible to receive?

\footnotetext{
${ }^{5}$ Instructing respondents to ignore inflation in the introductory statement below is potentially important, because we are asking respondents to forecast as much as fifty-two years into the future. Similar instructions were given to respondents in our exploratory study of student expectations of the returns to schooling (Dominitz and Manski, 1996).
} 
What is the percent chance (or chances out of 100) that you would be eligible to receive over $\$\{Y\}, 000$ of Social Security benefits per year, when you turn 70 ?

The responses to these questions may be used to estimate person-specific subjective probability distributions of benefit levels, conditional on eligibility for benefits. ${ }^{6}$ In combination with the reported probability of eligibility, we may estimate subjective unconditional distributions of benefits. ${ }^{7}$

\subsection{Face-To-Face Interview}

The more intensive face-to-face interviews were designed to complement the national telephone survey. A random sample of staff members at a midwestern university were asked essentially the same questions as the SEE respondents, plus additional open-ended questions intended to explore how they went about forming their expectations. ${ }^{8}$ In particular, following the questions eliciting expectations of Social Security benefits, respondents were asked

\footnotetext{
${ }^{6}$ As in Dominitz and Manski (1997a), we use a least-squares criterion to fit person-specific log-normal distributions to the responses to the sequence of probabilistic questions.

${ }^{7}$ For respondents who report a zero probability of eligibility, the unconditional distribution is necessarily degenerate at $\$ 0$. We do not elicit conditional probabilities of benefit levels from respondent who reported a zero chance of eligibility. These respondents are instead posed an open-ended question asking why there is "no chance you will be eligible to collect any Social Security retirement benefits."

${ }^{8}$ The one difference between the questions in SEE and in the face-to-face interviews concerned the thresholds for the probabilistic questions on benefit levels. The CATI software used in SEE enables application of a personspecific branching algorithm, but this was difficult to implement with the pencil-and-paper format of the face-toface interviews. Hence the same thresholds, ranging from $\$ 5,000$ to $\$ 25,000$, were posed to all respondents.
} 
Having answered these questions, please describe as best you can the considerations you had in mind when you were attempting to predict your Social Security retirement benefits.

The interview also includes a new segment eliciting perceptions of the current maximum annual Social Security benefit. Following an introductory statement, respondents were asked for their subjective probabilities of the maximum benefit exceeding various thresholds and then for a best point estimate. ${ }^{9}$ The segment closed with two open-ended questions. Here is the text:

Now think about Social Security benefits today. In particular, imagine a person who is now 70 years old. Suppose that this person retired from work at age 65 and began collecting benefits after working full time for 40 years. Suppose that, while working, this person had high enough income to be eligible for the maximum Social Security benefit that is currently paid.

What is the PERCENT CHANCE that this person currently receives over $\$\{\mathrm{Y}\}, 000$ of Social Security benefits per year?

If you had to choose one number, what would be your best estimate of the benefits that this person receives per year?

Describe as best you can the current system that the government now uses to determine social security benefits. What are the main factors in calculating the size of the benefit? And so on.

\footnotetext{
${ }^{9}$ SEE elicits subjective probabilities only on the occurrence of future events, not on the value of objective quantities such as the current maximum Social Security benefit. However, the Bayesian idea that persons express uncertainty through subjective probabilities applies equally well to objective quantities and to future events.
} 
When thinking about the previous question, please describe as best you can the sources from which you drew your information.

The interview concludes with a sequence of questions about expected income at age 70 from sources other than Social Security. Respondents report up to six probabilities corresponding to threshold values ranging from $\$ 10,000$ to $\$ 100,000$. An open-ended question concerning how these expectations were formed is asked as well. We do not analyze these data in this paper.

\section{Empirical Findings}

\subsection{SEE Data}

Sample Size, Response Rates, and Response Patterns

The analysis in this paper is based on the 1651 SEE interviews completed from July 1999, when the Social Security questions were introduced, through April 2001. Of the 1651 respondents, 1425 were age-eligible (i.e., under 70) for the Social Security questions. Of these, 1377 reported their chance of eligibility for benefits at age 70; thus the response rate to the eligibility question was 0.97 . Of these 1377 persons, 145 reported zero chance of receiving benefits. Hence 1232 persons were asked the questions eliciting lowest and highest possible benefits and the probabilities of benefits exceeding specified thresholds, conditional on eligibility. Of these 1232 persons, 790 gave responses that could be used to estimate personspecific subjective distributions; thus the response rate to this sequence of questions was 0.64. In 
all, we have unconditional subjective distributions of benefits for $935(145+790)$ persons. Our analysis focuses on these respondents, who constitute 0.66 of the age-eligible SEE sample members.

The overall response rate of 0.66 to the sequence of Social Security expectations questions is considerably lower than those that we have experienced asking SEE respondents to forecast simple binary events (typically 0.95 or more) and somewhat lower than our experience eliciting income expectations one-year-ahead (typically 0.80 ). Over 85.5 percent (378 out of 442) of the non-response occurs when respondents do not report lowest/highest possible benefits. Another 8.4 percent did not respond to all of the probability questions asked, and the remaining 6.1 percent gave complete reports that could not be used to estimate person-specific subjective distributions.

With one-third of the sample having at least partially missing data, it is important to understand the cross-sectional pattern of response to the degree possible. Table 1 shows that respondents and non-respondents have the same mean age. However, non-respondents are somewhat more likely to be female, less likely to be non-Hispanic whites, less likely to be labor force participants, and less likely to be high school or college graduates.

Figure 1 presents a kernel-smoothed estimate of the probability of non-response conditional on age. The figure shows a non-monotone pattern. The estimated non-response rate falls from a maximum of about 0.45 at age 21 to a minimum of about 0.25 at age 34 . It then rises to a second maximum of about 0.42 at age 57 and falls again to about 0.25 at age 69 . We have no ready explanation for this age pattern.

\section{Comparison with HRS Response Rates}


The rate of non-response to the SEE Social Security questions, while troubling to some degree, compares favorably with the rate of non-response to Social Security expectations questions posed in the Health and Retirement Study (HRS). The HRS questions were asked only of the most "financially knowledgeable" member of the household, and then only if this person was not receiving benefits at the time of interview. Each such respondent was first asked if he or she expects to receive a benefit "at some time in the future." If the response is "yes," the respondent is asked the expected age of inception of benefits (i.e., retirement age) and the expected amount of benefits "in today's dollars" conditional on receipt at that age. The exact wording of the HRS questions is appended to this paper, as is a graphical depiction of the comparison of response rates.

In the year 2000 survey, 4337 HRS respondents born after 1930 (i.e., under 70) were asked the yes/no expectations question, and 3745 said "yes." Of these, 3565 reported a valid retirement age, but only 2412 reported the expected level of benefits. Thus, information on the expected level of benefits was obtained from only $0.56(2412 / 4337)$ of the respondents queried about their Social Security expectations. ${ }^{10}$

Although differences in sampling frames and question sequences preclude precise comparison of the HRS and SEE response rates, we think that the difference stems largely from the HRS practice of eliciting expected benefit levels only from respondents who answer "yes" to

\footnotetext{
${ }^{10}$ Other evidence on HRS response rates has been reported by Gustman and Steinmeier (1999, 2001), who analyze the Social Security expectations data collected in the 1992 interview. They report a response rate of 0.49 among those who (1) say "yes" to the eligibility question, regardless of age, (2) give permission to link Social Security Administration (SSA) data on their earnings histories, and (3) actually have their records linked (Gustman and Steinmeier, 2001). Approximately three-fourths of HRS respondents are said to satisfy the latter two criteria. Hence, about two-thirds of those who responded "yes" to the eligibility question and who had linkable records reported an expected level of benefits.
} 
the eligibility question. ${ }^{11}$ We have more to say about this below.

\section{Eligibility Expectations}

Among the 1377 SEE respondents who report a valid probability of eligibility for benefits at age 70 , the mean subjective probability of eligibility is 0.57 and the median is 0.60 . Figure 2 presents kernel-smoothed quantiles of eligibility probabilities conditional on age. The overall pattern is striking, with older respondents tending to report much higher probabilities of eligibility than do younger ones. For example, the estimated median probability of eligibility is 0.40 at age $30,0.50$ at age $40,0.75$ at age 50, 0.95 at age 60 , and 1.00 at age 65 . Thus, older Americans tend to be almost certain that, in one form or another, the Social Security system will survive at least ten more years. However, younger Americans have no such confidence in the continuation of the system until their retirement.

The first two columns of Table 2 present least absolute deviations (LAD) estimates of best linear predictors that describe the cross-sectional variation of eligibility probabilities with demographic and economic covariates of the respondents. The estimates in the first column of the table are based on the 1277 SEE respondents who report their eligibility probability and covariates, while those in the second column are based on the smaller sample of 871 respondents who answer the entire sequence of expectations questions. Clearly age is the dominant predictor variable; in both samples, the predicted chance of eligibility for benefits increases by about one and one-half percentage points for every one-year increase in age. The other covariates have

\footnotetext{
${ }^{11}$ SEE respondents are adults who live in households with telephones, while respondents to the HRS Social Security expectations questions are "financially-knowledgeable" individuals who are not receiving Social Security and live in households satisfying HRS age restrictions.
} 
relatively little predictive power.

\section{Comparison with HRS Eligibility Expectations}

It is of interest to juxtapose the SEE and HRS eligibility questions and to compare the responses. The respective questions are:

SEE: Think ahead to when you are about to turn 70 years old and suppose that you are not working at that time. What is the PERCENT CHANCE that you will be eligible to collect any Social Security retirement benefits at that time?

HRS: Do you expect to receive Social Security benefits at some time in the future?

The questions and samples of respondents differ in several respects, but the main distinction is that the SEE question asks for a subjective probability while the HRS one asks for a yes/no response. Focusing on this distinction and abstracting from the others, responses to the two questions may be compared if we suppose that respondents asked the HRS question report best point predictions of benefit eligibility, obtained by minimizing the expected value of some symmetric loss function. As pointed out in Manski (1990), each respondent will answer "yes" if his or her subjective probability of eligibility exceeds a threshold that depends on the loss function and "no" if this probability is below the threshold. If the loss function is symmetric, the threshold probability is 0.5 . So a SEE respondent with subjective probability above 0.5 would report "yes" if asked the HRS question and one with subjective probability below 0.5 would report "no."

Figure 3 presents the actual fraction of HRS respondents of different ages who answer 
"yes" to the HRS eligibility question. The figure applies the reasoning of the paragraph above to estimate the fraction of SEE respondents who would have reported "yes" if they had been asked the HRS question. ${ }^{12}$ Comparison of the two plots shows that they are quite close to one another at all ages; the maximum deviation is only 0.05 .

This suggests that HRS respondents who report "yes" may reasonably be interpreted as having subjective eligibility probabilities in the range $[0.5,1]$ and those who report "no" as having probabilities in the range $[0,0.5]$. This interpretation calls into question the HRS practice of not eliciting expected benefit levels from those who report "no." Such persons, particularly those with non-negligible subjective probabilities of eligibility, may have well-formed beliefs regarding the benefits they would receive conditional on being eligible.

\section{Expectations of Benefit Levels: Central Tendency}

For each of the 790 SEE respondents with complete expectations data and a positive subjective probability of eligibility for benefits, we fit a person-specific log-normal distribution to the elicited probabilities that benefits exceed different thresholds. A succinct way to characterize these subjective distributions is through their medians, to express the central tendencies of respondents' expectations, and their interquartile ranges, to express respondents' uncertainty. In what follows, m denotes the median of a person's fitted log-normal distribution and q denotes its interquartile range. ${ }^{13}$

\footnotetext{
12 The estimates based on SEE data are kernel-smoothed. The HRS sample is large enough to eliminate the need for smoothing, so the actual year-by-year data are plotted. The HRS plot includes persons who currently receive benefits and assumes that such persons would have responded "yes" had they been asked the eligibility question. Among those who do not report "yes" are 741 respondents who report "no" and 80 who report "don't know."

13 It has been traditional in the literature on consumption and savings to measure central tendency and uncertainty by the mean and variance of subjective log-income. We could transform our elicited Social Security benefit
} 
The cross-sectional median value of $m$ across the sample of 790 respondents is $\$ 10,046$. According to SSA records, the average monthly benefit received in March 2001 by all beneficiaries age 65 or older was $\$ 817$, which equates to $\$ 9804$ annually. ${ }^{14}$ Among retired workers over age 65, the average benefit in March 2001 was $\$ 854$, or $\$ 10,248$ on an annual basis. These average figures for persons over 65 are not directly comparable to our crosssectional median of $\mathrm{m}$ for benefits at age 70 . However, the close correspondence of values does indicate that respondents have a reasonable general sense of the benefits they would receive, conditional on eligibility.

Figure 4 presents kernel-smoothed $0.25,0.50$, and 0.75 -quantile regressions of $\mathrm{m}$ on age. Observe that the 0.25 -quantile rises from about $\$ 2,500$ to $\$ 5,000$ as age increases from 20 to 35 and then remains close to $\$ 5,000$ as age increases from 35 to 69 . The 0.50 -quantile dwells in the range $\$ 7,000-\$ 10,000$ for persons of age $22-35$ and then in the range $\$ 10,000-\$ 12,000$ for persons older than 35 . The 0.75 -quantile remains between $\$ 15,000-\$ 20,000$ for all persons older than 21 .

The main impression that we draw from Figure 4 is that the central tendencies of persons' expectations of benefit levels vary relatively little with age. In contrast, Figure 2 showed that expectations of eligibility rise dramatically with age. Juxtaposing these findings, we conclude that younger persons tend to be much less confident than older ones that Social Security will continue to exist when they retire but, conditional on continued existence of the system, they

expectations into expectations of log-benefits, but we see no good reason to do so. Characterization of the central tendency and uncertainty by the subjective median and interquartile range of benefits seems to us much more natural and informative.

${ }^{14}$ See Table 1.B3 appended to this paper. Available at http://www.ssa.gov/statistics/cos/pdf/2000/1b3.pdf. 
tend to expect that benefits will remain near current levels.

Figure 4 also makes plain that expectations of benefit levels vary substantially among persons of any given age. For example, the interquartile range of $\mathrm{m}$ is about $\$ 15,000(\$ 20,000$ $\$ 5000)$ at age 40 and about $\$ 13,000(\$ 18,000-\$ 5,000)$ at age 60 . This heterogeneity in expectations presumably reflects a combination of real and perceptual factors. On the real side, the current system makes benefits vary with a person's own earnings and, in the case of survivor benefits, with the earnings of spouses; hence expectations should vary with personal and spousal past and expected labor earnings. On the perceptual side, persons may vary in their knowledge of how the Social Security system currently operates and in their expectations for the future structure of the system.

The third column of Table 3 presents LAD estimates of best linear predictors that describe the cross-sectional variation of $\mathrm{m}$ with various demographic and economic covariates of the respondents. Echoing Figure 4, we find that $\mathrm{m}$ varies little with age, increasing by only $\$ 66$ for every one-year increase in age. The variation with gender and schooling is more pronounced. Conditioning on other covariates, the predicted value of $\mathrm{m}$ is almost $\$ 3,000$ less for a women than for a man. This finding meshes nicely with current differences in benefits; Table 1.B3 shows that the average monthly benefit received in March 2001 by beneficiaries age 65 or older was $\$ 232$ higher for men than for women, which equates to a difference of $\$ 2,784$ annually. Conditioning on other covariates, individuals with schooling beyond high school are predicted to have subjective medians more than $\$ 2,000$ dollars higher than are individuals with no such schooling. This variation in expected benefits may reasonably arise from variation with schooling in life-cycle earnings streams. 
Expectations of Benefit Levels: Uncertainty

Across the sample of 790 SEE respondents with complete expectations data and a positive probability of eligibility for benefits, the cross-sectional median of the subjective interquartile range $\mathrm{q}$ is $\$ 7,049$. Figure 5 presents kernel-smoothed $0.25,0.50$, and 0.75 -quantile regressions of $\mathrm{q}$ on age. The figure shows that subjective uncertainty about the magnitude of Social Security benefits is very substantial among young persons but decreases continuously with age. The 0.25 -quantile of $q$ dwells near $\$ 5,000$ up to age 52 and then falls to zero by age 57. The 0.50 -quantile falls steadily from more than $\$ 15,000$ at age 20 to zero at age 67 . The 0.75-quantile falls very sharply (roughly from $\$ 38,000$ to $\$ 20,000$ ) from age 20 to 25 , and continues to fall steadily thereafter, reaching a limit of about $\$ 5,000$ at age 69 .

That uncertainty about benefit levels should decrease with age makes much sense, because uncertainty about future labor earnings and about the future structure of Social Security should decrease as retirement nears. However, we take the main message of Figure 5 to be that even middle-aged persons who are nearing retirement tend to be rather uncertain of their future benefit levels, conditional on eligibility. For example, the median value of $q$ is $\$ 8,000$ among respondents of age 55, who are typically only ten years from retirement. ${ }^{15}$

The final column of Table 3 presents LAD estimates of best linear predictors that describe the cross-sectional variation of $\mathrm{q}$ with various demographic and economic covariates of

\footnotetext{
${ }^{15}$ Analyzing the point expectations of future benefits elicited in the HRS, Gustman and Steinmeier $(1999,2001)$ conclude that respondents tend to misperceive the magnitude of the benefits they will receive. The pervasive uncertainty that SEE respondents reveal when questioned probabilistically makes us think that this conclusion is premature. We simply do not know how respondents who are uncertain of their future benefits choose point values when queried. Continuing the reasoning applied earlier to elicitation of eligibility, it may be that a person asked to provide a point prediction of his or her benefit level chooses a value that minimizes expected loss with respect to some loss function. If so, the reported value necessarily depends on the loss function used; the mean under square loss, the median under absolute loss, and so on.
} 
the respondents. The strong variation with age echoes Figure 5; the predicted value of $\mathrm{q}$ decreases by over $\$ 250$ dollars for every one-year decrease in age. The other covariates mainly have little predictive power. It appears, however, that non-Hispanic African Americans tend to be much more uncertain about their future benefit levels than do members of other ethnic groups.

\subsection{Face-To-Face Interview Data}

In this section, we analyze survey responses obtained from 49 staff members at a midwestern university. The face-to-face interviews provide two important kinds of information not obtained from the SEE respondents. First, they provide respondents' expectations regarding the magnitude of current Social Security benefits. Second, they provide responses to open-ended questions through which we seek to learn about respondents' information sources and thought processes.

\section{Sample Size and Response Rates}

Originally, 123 individuals were randomly selected from the university's staff directory and were solicited by e-mail to participate in a study of perceptions of the Social Security retirement system and its future. The message stated that the face-to-face interview would take no longer than 20-30 minutes and that $\$ 15$ compensation would be paid. Forty percent of the persons solicited (49/123) agreed to be interviewed. The persons interviewed responded to 
essentially all of the questions posed. ${ }^{16}$

Although the face-to-face survey suffered none of the item response problems encountered in the SEE telephone interviews, it did run up against another problem that SEE largely avoids. As noted in Section 3.2, respondents to the face-to-face survey were asked to report probabilities that Social Security benefits exceed a series of predetermined thresholds ranging from $\$ 5,000$ to $\$ 25,000$, rather than the SEE series of person-specific thresholds generated by responses to the earlier questions on smallest and largest possible benefits. We found that some of the 49 respondents place high probability on benefits exceeding our top threshold of $\$ 25,000$. We were able to estimate the subjective distributions of these respondents poorly, if at all.

Expectations of Maximum Current Social Security Benefits: Central Tendencies

We measure expectations of current benefits by eliciting respondents' subjective distributions of the amount now paid to a 70-year-old retired worker who is "eligible for the maximum social security benefit" after retiring at age 65 . We were able to estimate subjective distributions for 43 of the 49 respondents. We were not able to estimate distributions for the remaining 6 respondents, each of whom reported a 100 percent chance that the current maximum exceeds $\$ 25,000$.

Among the 43 respondents with fitted subjective distributions of maximum benefits, the cross-sectional median value of the subjective median is about $\$ 18,500$. The cross-sectional

\footnotetext{
${ }^{16}$ Two respondents declined to report the smallest and largest possible Social Security benefits that they might receive at age 70. However, these and all other respondents did answer the subsequent sequence of questions asking for the probability that their benefits would exceed various predetermined thresholds.
} 
median of respondents" point "best estimate" of the maximum benefit is $\$ 16,000$ for these 43 respondents, and $\$ 18,000$ for all 49 respondents. Based on information available from the Social Security Administration, we calculate the actual value of the maximum benefit to be $\$ 16,860 .^{17}$ Thus, the central tendencies of respondents' expectations tend to be reasonably in line with the facts.

In Section 4.1, we noted the absence of empirical evidence on how persons choose point estimates for quantities about which they are uncertain (see footnote 14). We can shed a bit of light on this matter by comparing the subjective medians and best estimates reported by the 43 respondents for whom we have complete data. Figure 6 displays the 43 pairs of (subjective median, best estimate) values. The reader should focus on the cases in which the subjective median is greater than our lowest threshold of $\$ 5000$ and less than our top threshold of $\$ 25,000$. In this region, a forty-five degree line through the origin provides a reasonably good overall fit to the data, with residuals that rarely exceed $\$ 5000$.

\section{Expectations of Maximum Current Social Security Benefits: Uncertainty}

Figure 7 displays the subjective interquartile ranges of respondents' subjective distributions, along with their subjective medians. The striking conclusion is that respondents tend to be very uncertain about the current maximum benefit, with most values being above $\$ 5000$, and many being above $\$ 10,000$. There is no evident association between respondents' subjective medians and subjective interquartile ranges.

\footnotetext{
17 A person who retired in 1996 at age 65 and was eligible for the maximum benefit received $\$ 1248$ per month at that time (see www.ssa.gov/OACT/COLA/exampleMax.html). Application of the yearly cost-of-living-adjustment (COLA) from 1996 onward shows that in 2001 this person, now 70 years old, receives $\$ 1405$ per month, or \$16,860 per year.
} 


\section{Expectations of Own Future Benefits and of Maximum Current Benefits}

Figures 8 and 9 compare respondents' expectations of maximum current benefits with their expectations of their own future benefits. Figure 8 plots respondents' subjective medians for these two quantities, while Figure 9 plots their subjective interquartile ranges.

Figure 8 shows a clear positive relationship between the two subjective medians. In most cases, the data lie somewhat below the 45-degree line, indicating that respondents expect their own benefit to be smaller than current benefits. This makes sense for two reasons. First, should the future formula remain the same as today's, some respondents may believe that their life-cycle earnings will not qualify them for the maximum benefits. Second, to the extent that respondents believe the future formula will differ from today's, the tenor of the recent public discussion of Social Security makes it reasonable to expect that benefits will fall rather than rise.

Figure 9 offers a glimpse of the relationship between "formula uncertainty" (i.e., uncertainty about the current amount paid to a retired worker with a specific earnings history) and the total uncertainty an individual perceives about benefits to be paid at age 70 , conditional on eligibility. The latter uncertainty includes not only formula uncertainty, but also earnings uncertainty and uncertainty about the future structure of the system. The figure indicates a weak positive relationship between formula uncertainty and total uncertainty. However, we do not

find that total uncertainty generally exceeds formula uncertainty. As often as not, the interquartile range of maximum current benefits exceeds that of own future benefits.

\section{Open-Ended Responses}

In response to open-ended questions, subjects described for us their understanding of the 
Social Security system, as well as the information on which their understanding is based. The dominant source of information reported by respondents is the annual statement that workers now receive from the SSA. Fully 43 of the 49 respondents indicated that they based their expectations on SSA mailings, with the majority clearly describing the annual report. Other than these documents, no strong pattern emerged. Several respondents indicated that they infer the level of benefits from observation of or conversations with relatives or acquaintances currently collecting benefits.

Our introduction to the module on future benefit expectations informed respondents that current benefits are "determined by retirement age and by earnings prior to retirement." When later asked to describe the factors that currently determine benefits, more than half of the respondents indicated a link between earnings histories and benefits. However, the responses rarely suggested a full understanding of the formula. Some respondents expressed a belief that benefits are based on earnings at retirement or over the preceding few years, as is common in employer-provided defined-benefit pension plans. Six respondents expressed a belief that benefits are mean-tested, and one speculated that benefits would be means-tested in the future.

\section{$\underline{\text { 5. Simulating the Impact of Social Security Policy on Retirement Savings }}$}

In this section we use the decision model of Section 2 and the empirical findings of Section 4 to simulate how Social Security policy may affect retirement savings. It would be too much to claim that this simulation exercise provides credible forecasts of policy impacts - the model of Section 2 is much too idealized and the findings of Section 4 provide only part of the 
empirical knowledge necessary to enable realistic forecasts. We perform the simulations primarily to illustrate how our empirical analysis of expectations data may be used to predict the behavioral responses to revisions to the Social Security system. We also think that the simulations provide some insight into the potential direction and magnitude of these responses. Section 5.1 describes the simulation scenarios and Section 5.2 reports the findings.

\subsection{Simulation Scenarios}

\section{Maintained Assumptions}

The simulations performed here suppose that period 1 and period 2 are of the same length. One way to think of the simulations is to imagine a person of age 45 who will work until age 65 and then live in retirement until age 85; then each period is 20 years in length. Suppose that this person has not saved for retirement prior to age $45 .{ }^{18}$ At age 45 , the person knows that he will receive income $\mathrm{y}_{1} \equiv \mathrm{Y}_{1} / 20$ each year until retirement and decides on some fixed annual allocation of this income between consumption and retirement savings. For simplicity, suppose that the savings allocated each year must be consumed exactly 20 years later; that is, retirement savings allocated at age 48 will be consumed at age 68 , and so on. These assumptions allow us to describe scenarios entirely in terms of annual income, consumption, and savings; annual quantities are simpler to think about than are the corresponding quantities expressed in terms of 20-year periods.

We consider a person who discounts the future at one percent per year and whose utility

\footnotetext{
${ }^{18}$ One may instead think of first-period income $\mathrm{Y}_{1}$ as inclusive of accumulated savings. Alternatively, we could change the model by adding accumulated pension savings that cannot be spent in period 1 .
} 
function exhibits constant relative risk aversion with coefficient equal to 4; thus we set

$$
u(c)=\frac{c^{1-\gamma}}{1-\gamma} ; \quad \gamma=4 ; \quad \beta=0.99
$$

where $\mathrm{c}$ is consumption in a given year and $\mathrm{u}($.$) is annual utility. These preference assumptions$ are motivated in part by the findings of Barsky et al. (1997) and Carroll (2001). Analyzing responses to hypothetical choice questions in the HRS, Barsky et al. (1997) report that a majority of respondents do not discount future consumption and that almost two-thirds make choices consistent with a value of $\gamma$ that exceeds 3.76. The specific value $\gamma=4$ is within the range $1-5$ that Carroll (2001, p. 28) states is "generally considered plausible." Abel (2001) uses the discount rate of 1 percent per year and considers a period that is 25 years long.

We consider persons whose pre-tax income is either $\$ 80,000$ or $\$ 25,000$ per year. Applying reasonable tax rates and employer contributions to a retirement plan, these amounts imply net incomes of $\$ 55,000$ or $\$ 20,000$, respectively. We use the pre-tax incomes to calculate OASDI taxes and to specify amounts to be placed into personal retirement accounts.

\section{Baseline Expectations Assumptions}

We use the empirical findings of Section 4.1 to specify baseline values for the subjective distribution $\mathrm{P}\left(\mathrm{y}_{2}\right)$ of annual Social Security benefits. We consider someone early on in the first period, specifically at age 50. These respondents were asked to report expectations for benefits 20 years hence, at age 70. Figure 2 shows that, among such persons, the median subjective probability of eligibility for benefits is 0.75 . Figures 4 and 5 show that, among such persons, the 
median values of $\mathrm{m}$ and $\mathrm{q}$ are about $\$ 10,000$ and $\$ 7,000$ respectively. For the person with net income of $\$ 20,000$ per year, we use these values of $(m, q)$ to specify Social Security benefit expectations prior to any change in Social Security policy. For the person with net income of $\$ 55,000$ per year, we specify larger baseline values of $(\mathrm{m}, \mathrm{q})$, namely $(\$ 16,000, \$ 9,600) .{ }^{19}$

Specification of the distribution $\mathrm{P}\left(\mathrm{y}_{2}\right)$ does not suffice to express expectations; we need to specify expectations for stock market returns $\mathrm{r}^{\mathrm{m}}$ as well. To simplify the simulations, we suppose that $\mathrm{y}_{2}$ and $\mathrm{r}^{\mathrm{m}}$ are subjectively statistically independent; that is, $\mathrm{P}\left(\mathrm{y}_{2}, \mathrm{r}^{\mathrm{m}}\right)=\mathrm{P}\left(\mathrm{y}_{2}\right) \mathrm{P}\left(\mathrm{r}^{\mathrm{m}}\right)$. Furthermore, we consider a person for whom the subjective distribution of the annualized rate of return is uniform on the discrete values

$$
\{-0.01,0.01,0.02,0.03,0.04,0.05,0.06,0.07,0.08,0.10\}
$$

The subjective means of the annual and cumulative rates of return over the 20 -year period in which savings are set aside are therefore specified to be $4.5 \%$ and $186 \%$, respectively. ${ }^{20}$ The risk-free annual rate is assumed to be $1.0 \%$, yielding a cumulative return of $22 \%$ over the 20 -year period. ${ }^{21}$ Thus, the annual equity premium is specified to be $3.5 \%$, and the subjective probability that equity returns will fall short of the risk-free rate over the 20-year span is just 0.10 .

\footnotetext{
${ }^{19}$ These amounts were chosen to approximate the SEE estimates of the median values of $(\mathrm{m}, \mathrm{q})$ for persons with pre-tax incomes of $\$ 25,000$ or of $\$ 80,000$. These estimates are $(\$ 9,100, \$ 6,800)$ and $(\$ 15,500, \$ 9,600)$, respectively. ${ }^{20}$ This subjective distribution is chosen to approximately yield the findings of Feldstein and Ranguelova (2001), who assume that the log level of a diversified portfolio (60\% S\&P 500 index and 40\% Salomon Brothers corporate bond index) follows a random walk with drift. They choose a mean return of $5.5 \%$ with a standard deviation of $12.5 \%$. Our discrete distribution approximates such a process over a 20 -year span, but with a mean annual return of $4.5 \%$ and a standard deviation of $15.0 \%$.

${ }^{21}$ Abel (2001) uses a risk-free rate of $1.19 \%$. Note also our specification follows the convention that $\beta=\left(1+r^{f}\right)^{-1}$.
} 


\section{How Policy Affects Expectations}

We suppose that changes in Social Security policy affect $\mathrm{P}\left(\mathrm{y}_{2}\right)$, but not $\mathrm{P}\left(\mathrm{r}^{\mathrm{m}}\right)$. We consider two policy changes, which could be implemented separately or in combination. These are:

(a) A lockbox proposal that removes the threat of system collapse. Specifically, we suppose that the policy change increases the person's subjective probability of eligibility for benefits but does not change his subjective distribution of benefits conditional on eligibility.

(b) A private investment proposal that places 5 percent of pre-tax earnings in a personal retirement account mutual fund bearing real rate of return $\mathrm{r}^{\mathrm{m}}$. The remainder of the OASDI taxes (i.e., $7.4 \%$ of pre-tax earnings) is used to fund continuation of the current definedbenefit program. Under this proposal, the person's subjective probability of eligibility for defined benefits remains as at present, whereas the defined contributions placed in personal retirement accounts are perceived to be available with certainty (i.e., fully vested). The subjective distribution of defined Social Security benefits, conditional on eligibility, is

specified to be log-normal with median $\mathrm{m} \cdot \frac{0.074}{0.124}$. The interquartile range is specified to be either $\mathrm{q}$ or $\mathrm{q} \cdot \frac{0.074}{0.124}$.

(c) A proposal that combines proposals (a) and (b).

\subsection{Simulation Findings}


The simulation findings are presented in Table 3. The left panel of the table specifies eighteen different scenarios. Each scenario is defined by

- a value of net annual income while working $(\$ 55,000$ or $\$ 20,000)$

- a log-normal subjective distribution of Social Security defined benefits conditional on eligibility (parameterized by values for $\mathrm{m}$ and $\mathrm{q}$ )

- a subjective probability of eligibility for benefits $(0.75 ; 0.90$; or 1.00$)$

- a dollar amount per year of OASDI taxes placed in a private investment account $(\$ 0 ; \$ 4,000$ or $\$ 1,250$ ).

The cumulative impact of the policy changes on benefits expectations may be ascertained from the columns that report five quantiles of the subjective unconditional distribution of the Social Security benefit portfolio, which is composed of both the defined-benefit and the definedcontribution components. The last three columns of the table report the optimal annual consumption and savings in each scenario.

This table nicely summarizes how specified policy changes could affect the social security expectations and consumption/savings decisions of some hypothetical agents. Clearly, simulations could be conducted for persons with other characteristics, perhaps for each member of the SEE sample. However, such an analysis would push the model and the available data more than we believe is justified, and the results could not be presented so succinctly. We believe that performance of more extensive simulations aiming to predict the population distribution of consumption/savings decisions can potentially do much to inform the design and evaluation of social security policy. However, we think it prudent not to perform such simulations until richer data on expectations can be collected and joined with more realistic behavioral models. 


\section{Person with \$55,000 Net Annual Income}

Simulations (1) through (6) consider the person who earns $\$ 55,000$ net annual income while working. Under the baseline simulation (1), this person consumes $\$ 35,900$ per year while working and allocates $\$ 19,100$ to savings, with $\$ 13,600$ placed in the mutual fund and $\$ 5,500$ in the risk-free asset. Simulations (2) and (3) consider the lockbox proposal and suppose that, as a consequence, the person raises his subjective probability of eligibility from 0.75 to 0.90 or to 1.00. The result is that consumption while working rises from $\$ 35,900$ to $\$ 37,400$ or $\$ 39,600$ respectively. Total savings must, of course, decline commensurately. Nevertheless, savings placed in the mutual fund actually rises, from $\$ 13,600$ to $\$ 14,000$ or $\$ 15,400$ respectively. Only savings in the risk-free asset falls, from $\$ 5,500$ to $\$ 3,600$ or $\$ 0$ respectively.

Simulations (4) through (9) include investment of $\$ 4,000$ of OASDI taxes in a personal retirement account mutual fund. At the same time, the median of the subjective distribution of defined benefits, conditional on eligibility, falls to about $\$ 9,500$. The optimal allocation does not vary much with respect to variation in the subjective interquartile range, which is specified to either stay fixed at $\$ 9,600$ or decline proportionately to about $\$ 5,700$. Either way, the reduction in the amount of discretionary savings placed in the mutual fund does not fully offset the mandated $\$ 4,000$ investment, falling by $\$ 2,300$ to $\$ 3,500$. When the individual is certain of benefit eligibility, first-period consumption falls slightly relative to the baseline scenario, by just $\$ 100$ or $\$ 300$. When benefit eligibility is uncertain, first-period consumption rises by $\$ 1,000$ to $\$ 1,700$. Thus, the offset of risky investment is greater when eligibility for regular benefits is more likely, whereas the consumption increase is greater when benefit eligibility is less likely.

When considering these results, it should be noted that the changes to Social Security policy affect both the central tendency and spread of the Social Security benefit portfolio (i.e., 
defined benefits and personal retirement account funds). Our parameterization of the lockbox policy simply removes the lower tail of the distribution, which clearly increases expected utility as it increases the central tendency and decreases uncertainty. Our mixed DB-DC scenario also increases the expected value of the portfolio while, in some cases, decreasing indicators of uncertainty such as the interquartile range.

\section{Person with $\$ 20,000$ Net Annual Income}

Simulations (10) through (18) consider the person who earns $\$ 20,000$ per year while working. Under the baseline simulation (10), this person consumes $\$ 13,300$ per year while working and allocates $\$ 6,300$ to savings, with $\$ 4,600$ placed in the mutual fund and $\$ 2,100$ in the risk-free asset. Simulations (11) and (12) consider the lockbox proposal and suppose that, as a consequence, the person raises his subjective probability of eligibility from 0.75 to 0.90 or to 1.00. The result is that consumption while working rises from $\$ 13,300$ to $\$ 14,000$ or $\$ 15,500$ respectively. The increase in consumption comes almost entirely out of risk-free savings.

Simulations (13) through (18) include investment of $\$ 1,250$ of OASDI taxes in a personal retirement account. Once again, the reduction in discretionary mutual fund investment does not fully offset the mandated investment, and, relative to the corresponding baseline scenario, firstperiod consumption increases when eligibility is uncertain but decreases when eligibility is certain.

Observe that under the expectations assumptions of scenarios (16) through (18), Social Security proposals with a personal retirement account component yield subjective distributions of benefits that are in some respects inferior to the distributions in scenarios (10) through (13), which assume continuation of the present defined-benefit system. This contrasts with our 
findings for the person with $\$ 55,000$ income, for whom the investment-based system shifts the entire upper half of the subjective distribution to the right by at least several thousand dollars; compare scenarios (7) through (9) with scenarios (1) through (3). Thus, we forecast that moving from a pure defined-benefit system to one combining defined benefits and defined contributions could have regressive distributional effects. According to Feldstein and Liebman (2001), advocates of a mixed system argue that these effects may be offset by increasing the definedbenefits component so as to redistribute some gains from higher to lower income individuals. We have not simulated such a policy.

\section{Subjective Benefit Uncertainty and Objective Benefit Outcomes}

We have viewed the behavioral response to Social Security policy changes through the lens of an idealized model of retirement savings decisions. The decision makers in our simulations, like the respondents to the SEE, perceive a substantial probability of receiving no benefits after they retire. Therefore, policies that ensure receipt have the potential to greatly enhance subjective expected utility.

We have considered two such policies-the Social Security lockbox and personal retirement accounts. In our simulations, these policies tend both to increase the central tendency of benefit expectations and to reduce uncertainty via elimination of perceived risks of zero benefits. Such perceived welfare enhancing properties suggest that these policy reforms would receive widespread public support.

It is important to keep in mind that subjective benefit uncertainty need not correspond to objective risks. The benefit distributions shown in Table 3 are subjective in nature, not objective. Whereas individuals fearful of a collapse of the system may perceive high 
probabilities of zero benefits, these subjective expectations may not reflect political realities. Whereas individuals may not fully understand the formula now used to compute benefits, policy makers face no such uncertainty. For these and similar reasons, the benefit distributions shown in Table 3 may not accurately portray the benefits that persons would actually receive under alternative Social Security policies.

\section{Conclusion}

The empirical findings reported in Section 4 add substantially to the rather limited empirical evidence that was previously available on Social Security expectations. The SEE findings on the variation of expectations with age are particularly interesting. We found that younger persons tend to be much less confident than older ones that Social Security will continue to exist when they retire. We estimate the median subjective probability of eligibility for benefits to be 0.40 at age $30,0.50$ at age $40,0.75$ at age $50,0.95$ at age 60 , and 1.00 at age 65 . We also found that, conditioning on continued existence of the system, younger persons and older ones both tend to expect that benefits will remain near current levels. Hence the prevalent concern among younger persons appears to be that the Social Security system will collapse entirely, not that benefits will be reduced.

Also notable is the extent of uncertainty about benefit levels. The SEE data show that even middle-aged persons who are nearing retirement tend to have large subjective interquartile ranges for their future benefit levels, conditional on eligibility. These persons face relatively little uncertainty about their future labor earnings or about the future structure of the Social 
Security system, so the main source of their uncertainty about benefits must be uncertainty about the formula determining current benefits. Our face-to-face interviews provide direct empirical evidence that formula uncertainty is substantial.

The expectations data analyzed here provide some of the empirical evidence necessary to forecast how proposed changes in Social Security policy would affect retirement savings. The simulations performed in Section 5 provide some sense of the impacts that may occur, but realistic forecasting of policy impacts requires other empirical evidence (as well as a less idealized decision model). For one thing, we need to know the expectations that persons hold for the returns to private savings. For another, we need to understand how changes in policy would affect the expectations that persons hold. And, of course, forecasting savings decisions requires empirical evidence on preferences. 


\section{$\underline{\text { References }}$}

Abel, A. (2001). "The Effects of Investing Social Security Funds in the Stock Market When Fixed Costs Prevent Some Households from Holding Stocks," American Economic Review, 91, 128-148.

Barsky, R., F. T. Juster, M. Shapiro, and M. Kimball (1997), "Preference Parameters and Behavioral Heterogeneity: An Experimental Approach in the Health and Retirement Study," Quarterly Journal of Economics, 112, 537-579.

Bernheim, B. D. (1988). "Social Security Benefits: An Empirical Study of Expectations and Realizations," in R.R. Campbell and E. Lazear, eds., Issues in Contemporary Retirement, Stanford, CA: Hoover Institution.

Campbell, J. and M. Feldstein, eds. (2001), Risk Aspects of Investment-Based Social Security Reform, Chicago: University of Chicago Press.

Campbell, J., J. Cocco, F. Gomes, and P. Maenhout (2001). "Investing Retirement Wealth: A Life-Cycle Model," in in J. Campbell and M. Feldstein, eds., Risk Aspects of Investment-Based Social Security Reform, Chicago: University of Chicago Press.

Carroll, C. (2001), "A Theory of the Consumption Function, With and Without Liquidity Constraints," Journal of Economic Perspectives, 15, 23-45.

Dominitz, J. (1998), "Earnings Expectations, Revisions, and Realizations," $\underline{\text { Review of }}$ Economics and Statistics, 80, 374-388.

Dominitz, J. (2001). "Estimation of Income Expectations Models Using Expectations and Realizations," Journal of Econometrics, 102, 165-195.

Dominitz, J. and C. Manski (1996). "Eliciting Student Expectations of the Returns to Schooling," Journal of Human Resources, 31, 1-26.

Dominitz, J. and C. Manski (1997a). "Using Expectations Data to Study Subjective Income Expectations," Journal of the American Statistical Association, 92, 855-867.

Dominitz, J. and C. Manski (1997b). "Perceptions of Economic Insecurity: Evidence from the Survey of Economic Expectations,” Public Opinion Quarterly, 61, 261-287.

Feldstein, M., and J. Liebman (2001). “Social Security,” NBER Working Paper 8451.

Feldstein, M., and E. Ranguelova (2001). "Individual Risk in an Investment-Based Social Security System,” American Economic Review, 91, 1116-1125.

Feldstein, M., E. Ranguelova, and A. Samwick (2001). "The Transition to Investment-Based 
Social Security When Portfolio Returns and Capital Profitability are Uncertain," in J. Campbell and M. Feldstein, eds., Risk Aspects of Investment-Based Social Security Reform, Chicago: University of Chicago Press.

Gustman, A. and T. Steinmeier (1999). "What People Don't Know About Their Pensions and Social Security: An Analysis Using Linked Data from the Health and Retirement Study," NBER Working Paper 7368.

Gustman, A. and T. Steinmeier (2001). "Imperfect Knowledge, Retirement, and Savings," NBER Working Paper 8406.

Manski, C. (1990). "The Use of Intentions Data to Predict Behavior: A Best-Case Analysis," Journal of the American Statistical Association, 85, 934-940.

Manski, C. and J. Straub (2000), "Worker Perceptions of Job Insecurity in the Mid-1990s: Evidence from the Survey of Economic Expectations," Journal of Human Resources 35, 447479.

McHale, J. (2001). "The Risk of Social Security Benefit-Rule Changes: Some International Evidence," in J. Campbell and M. Feldstein, eds., Risk Aspects of Investment-Based Social Security Reform, Chicago: University of Chicago Press.

Merton, R. (1983). "On the Role of Social Security as a Means for Efficient Risk Sharing in an Economy Where Human Capital is Not Tradable," in Z. Bodie and J. Shove, eds., Financial Aspects of the United States Pension System, Chicago: University of Chicago Press. 


\begin{tabular}{|c|c|c|c|}
\hline \multicolumn{3}{|c|}{ Table 1. Descriptive Statistics: Survey of Economic Expectations 1999-2001 } \\
\hline Variable & $\begin{array}{c}\text { All Age Eligible } \\
\text { (1425 observations) }\end{array}$ & $\begin{array}{c}\text { Respondents } \\
\text { (935 observations })\end{array}$ & $\begin{array}{c}\text { Non-Respondents } \\
(490 \text { observations })\end{array}$ \\
\cline { 2 - 3 } Age (years) & $\frac{\text { sample mean }}{\text { sample mean }}$ & $\frac{\text { sample mean }}{42.3}$ \\
Female & 42.3 & 42.3 & 0.563 \\
In Labor Force & 0.515 & 0.490 & 0.773 \\
High School Graduate & 0.802 & 0.817 & 0.886 \\
Bachelor's Degree or More & 0.927 & 0.948 & 0.386 \\
White, Non-Hispanic & 0.411 & 0.424 & 0.745 \\
African-American, Non-Hispanic & 0.802 & 0.831 & 0.081 \\
Married and Residing with Spouse & 0.072 & 0.067 & 0.501 \\
Widowed & 0.539 & 0.559 & 0.035 \\
Cohabiting with Partner & 0.035 & 0.035 & 0.082 \\
\hline
\end{tabular}




\begin{tabular}{|c|c|c|c|c|}
\hline Predictor Variable & $\begin{array}{l}\text { Percent Chance of } \\
\text { Eligibility at Age } 70 \\
\text { (all respondents) }\end{array}$ & $\begin{array}{l}\text { Percent Chance of } \\
\text { Eligibility at Age } 70 \\
\text { (respondents with } \\
\text { complete data) }\end{array}$ & $\begin{array}{l}\text { Median } m \text { of Benefits } \\
\text { (\$), Conditional on } \\
\text { Eligibility }\end{array}$ & $\begin{array}{l}\text { IQR q of Benefits } \\
\text { (\$), Conditional on } \\
\text { Eligibility }\end{array}$ \\
\hline Age (years) & $\begin{array}{c}1.42 \\
(0.11)\end{array}$ & $\begin{array}{c}1.65 \\
(0.11)\end{array}$ & $\begin{array}{c}66.20 \\
(34.59)\end{array}$ & $\begin{array}{l}-253.21 \\
(35.74)\end{array}$ \\
\hline Female & $\begin{array}{l}-7.50 \\
(2.39)\end{array}$ & $\begin{array}{l}-3.30 \\
(2.72)\end{array}$ & $\begin{array}{l}-2929.89 \\
(937.80)\end{array}$ & $\begin{array}{c}428.42 \\
(627.19)\end{array}$ \\
\hline Labor Force Participant & $\begin{array}{l}-1.25 \\
(1.93)\end{array}$ & $\begin{array}{l}-1.10 \\
(3.42)\end{array}$ & $\begin{array}{c}1169.09 \\
(1114.75)\end{array}$ & $\begin{array}{c}819.63 \\
(896.40)\end{array}$ \\
\hline $\begin{array}{c}\text { Some School After } \\
\text { High School }\end{array}$ & $\begin{array}{l}-3.01 \\
(3.28)\end{array}$ & $\begin{array}{l}-2.21 \\
(3.98)\end{array}$ & $\begin{array}{c}2315.66 \\
(1122.79)\end{array}$ & $\begin{array}{c}153.99 \\
(804.11)\end{array}$ \\
\hline $\begin{array}{c}\text { Bachelor's Degree or } \\
\text { More }\end{array}$ & $\begin{array}{c}0.00 \\
(3.22)\end{array}$ & $\begin{array}{l}2.76 \\
(3.51)\end{array}$ & $\begin{array}{l}2634.96 \\
(1164.79)\end{array}$ & $\begin{array}{l}1001.50 \\
(830.90)\end{array}$ \\
\hline White, Non-Hispanic & $\begin{array}{l}2.27 \\
(4.08)\end{array}$ & $\begin{array}{c}0.71 \\
(7.76)\end{array}$ & $\begin{array}{c}2021.71 \\
(1737.73)\end{array}$ & $\begin{array}{c}1104.16 \\
(1467.01)\end{array}$ \\
\hline $\begin{array}{l}\text { African American, } \\
\text { Non-Hispanic }\end{array}$ & $\begin{array}{l}2.44 \\
(6.50)\end{array}$ & $\begin{array}{l}1.26 \\
(9.88)\end{array}$ & $\begin{array}{l}2194.33 \\
(2309.87)\end{array}$ & $\begin{array}{c}4609.23 \\
(2427.46)\end{array}$ \\
\hline $\begin{array}{l}\text { Married and Residing } \\
\text { with Spouse }\end{array}$ & $\begin{array}{l}-4.66 \\
(2.64)\end{array}$ & $\begin{array}{l}-3.86 \\
(2.96)\end{array}$ & $\begin{array}{l}-308.84 \\
(900.39)\end{array}$ & $\begin{array}{l}1248.94 \\
(734.27)\end{array}$ \\
\hline Widowed & $\begin{array}{l}-0.57 \\
(5.08)\end{array}$ & $\begin{array}{l}-0.55 \\
(3.38)\end{array}$ & $\begin{array}{c}1329.95 \\
(2452.33)\end{array}$ & $\begin{array}{c}1228.83 \\
(1178.72)\end{array}$ \\
\hline Cohabiting with Partner & $\begin{array}{l}-5.23 \\
(8.34)\end{array}$ & $\begin{array}{l}-9.21 \\
(7.15)\end{array}$ & $\begin{array}{c}885.97 \\
(2331.92)\end{array}$ & $\begin{array}{c}-826.28 \\
(2785.09)\end{array}$ \\
\hline Intercept & $\begin{array}{c}8.64 \\
(7.54)\end{array}$ & $\begin{array}{c}-7.64 \\
(10.58)\end{array}$ & $\begin{array}{c}4025.37 \\
(2641.77)\end{array}$ & $\begin{array}{l}15685.50 \\
(2878.48)\end{array}$ \\
\hline Number of Observations & 1277 & 871 & 745 & 745 \\
\hline
\end{tabular}

Bootstrap standard errors are reported in parentheses. Other than Age, all predictors are dichotomous. 


\begin{tabular}{|c|c|c|c|c|c|c|c|c|c|c|c|c|c|}
\hline \multirow{5}{*}{$\begin{array}{l}\text { Simulation } \\
\text { Number }\end{array}$} & \multicolumn{13}{|c|}{ Table 3. Simulated Responses to Changes in Social Security Program and Benefit Expectations } \\
\hline & \multicolumn{10}{|c|}{ Scenario* $^{*}$} & \multirow{2}{*}{\multicolumn{3}{|c|}{$\begin{array}{c}\text { Consumption and Savings } \\
\text { Allocation } \\
\end{array}$}} \\
\hline & & & bjective & xpectations & of Social Sect & rity B & nefit P & ortfolic & & & & & \\
\hline & \multirow{2}{*}{$\begin{array}{c}\text { Net Annual } \\
\text { Income } \\
Y_{1}\end{array}$} & \multicolumn{2}{|c|}{$\begin{array}{c}\text { Defined Benefits, } \\
\text { Conditional on Eligibility }\end{array}$} & \multirow{2}{*}{$\begin{array}{l}\text { Probability } \\
\text { of Eligibility } \\
\text { for Defined } \\
\text { Benefits }\end{array}$} & \multirow{2}{*}{$\begin{array}{c}\text { Personal } \\
\text { Retirement } \\
\text { Account } \\
\text { Defined } \\
\text { Contribution }\end{array}$} & \multicolumn{5}{|c|}{$\begin{array}{c}\text { Quantiles of Unconditional } \\
\text { Distribution of Social Security } \\
\text { Benefit Portfolio }\end{array}$} & \multirow{2}{*}{$\frac{\text { Consumption }}{\mathrm{C}_{1}}$} & \multicolumn{2}{|c|}{ Savings (S) } \\
\hline & & $\mathrm{m}$ & q & & & 0.10 & 0.25 & 0.50 & 0.75 & 0.90 & & $S^{m}$ & $S^{\dagger}$ \\
\hline (1) & 55 & 16.00 & 9.60 & 0.75 & 0.00 & 0.0 & 0.0 & 13.3 & 19.3 & 26.0 & 35.9 & 13.6 & 5.5 \\
\hline (2) & 55 & 16.00 & 9.60 & 0.90 & 0.00 & 0.0 & 10.5 & 15.1 & 20.7 & 27.3 & 37.4 & 14.0 & 3.6 \\
\hline (3) & 55 & 16.00 & 9.60 & 1.00 & 0.00 & 9.1 & 11.9 & 16.0 & 21.5 & 28.1 & 39.6 & 15.4 & 0.0 \\
\hline (4) & 55 & 9.55 & 9.60 & 0.75 & 4.00 & 7.2 & 12.1 & 18.6 & 26.9 & 36.1 & 37.5 & 11.1 & 6.4 \\
\hline (5) & 55 & 9.55 & 9.60 & 0.90 & 4.00 & 9.6 & 13.9 & 20.2 & 28.8 & 37.8 & 38.4 & 11.4 & 5.2 \\
\hline (6) & 55 & 9.55 & 9.60 & 1.00 & 4.00 & 11.1 & 15.2 & 21.4 & 30.0 & 38.8 & 39.2 & 11.9 & 3.9 \\
\hline (7) & 55 & 9.55 & 5.73 & 0.75 & 4.00 & 7.2 & 12.8 & 18.5 & 25.3 & 32.4 & 37.6 & 11.2 & 6.2 \\
\hline (8) & 55 & 9.55 & 5.73 & 0.90 & 4.00 & 10.6 & 14.6 & 19.6 & 26.3 & 33.6 & 38.5 & 11.7 & 4.8 \\
\hline (9) & 55 & 9.55 & 5.73 & 1.00 & 4.00 & 12.3 & 15.6 & 20.5 & 26.8 & 34.3 & 39.5 & 12.4 & 3.1 \\
\hline (10) & 20 & 10.00 & 7.00 & 0.75 & 0.00 & 0.0 & 0.0 & 8.0 & 12.4 & 17.6 & 13.3 & 4.6 & 2.1 \\
\hline (11) & 20 & 10.00 & 7.00 & 0.90 & 0.00 & 0.0 & 6.1 & 9.3 & 13.5 & 18.6 & 14.0 & 4.6 & 1.4 \\
\hline (12) & 20 & 10.00 & 7.00 & 1.00 & 0.00 & 5.2 & 7.1 & 10.0 & 14.1 & 19.2 & 15.5 & 4.5 & 0.0 \\
\hline (13) & 20 & 5.97 & 7.00 & 0.75 & 1.25 & 2.3 & 4.8 & 8.1 & 12.5 & 18.9 & 13.8 & 4.0 & 2.3 \\
\hline (14) & 20 & 5.97 & 7.00 & 0.90 & 1.25 & 3.8 & 5.8 & 9.1 & 13.8 & 20.4 & 14.3 & 4.1 & 1.7 \\
\hline (15) & 20 & 5.97 & 7.00 & 1.00 & 1.25 & 4.8 & 6.7 & 9.9 & 14.5 & 21.2 & 14.8 & 4.4 & 0.8 \\
\hline (16) & 20 & 5.97 & 4.18 & 0.75 & 1.25 & 2.3 & 5.2 & 8.4 & 11.5 & 14.9 & 13.8 & 4.0 & 2.2 \\
\hline (17) & 20 & 5.97 & 4.18 & 0.90 & 1.25 & 4.5 & 6.6 & 9.1 & 12.2 & 15.5 & 14.4 & 4.2 & 1.5 \\
\hline (18) & 20 & 5.97 & 4.18 & 1.00 & 1.25 & 5.7 & 7.3 & 9.7 & 12.6 & 15.9 & 15.1 & 4.8 & 0.1 \\
\hline
\end{tabular}


Figure 1. Nonresponse Probability for Social Security Expectations Questions, Conditional on Age

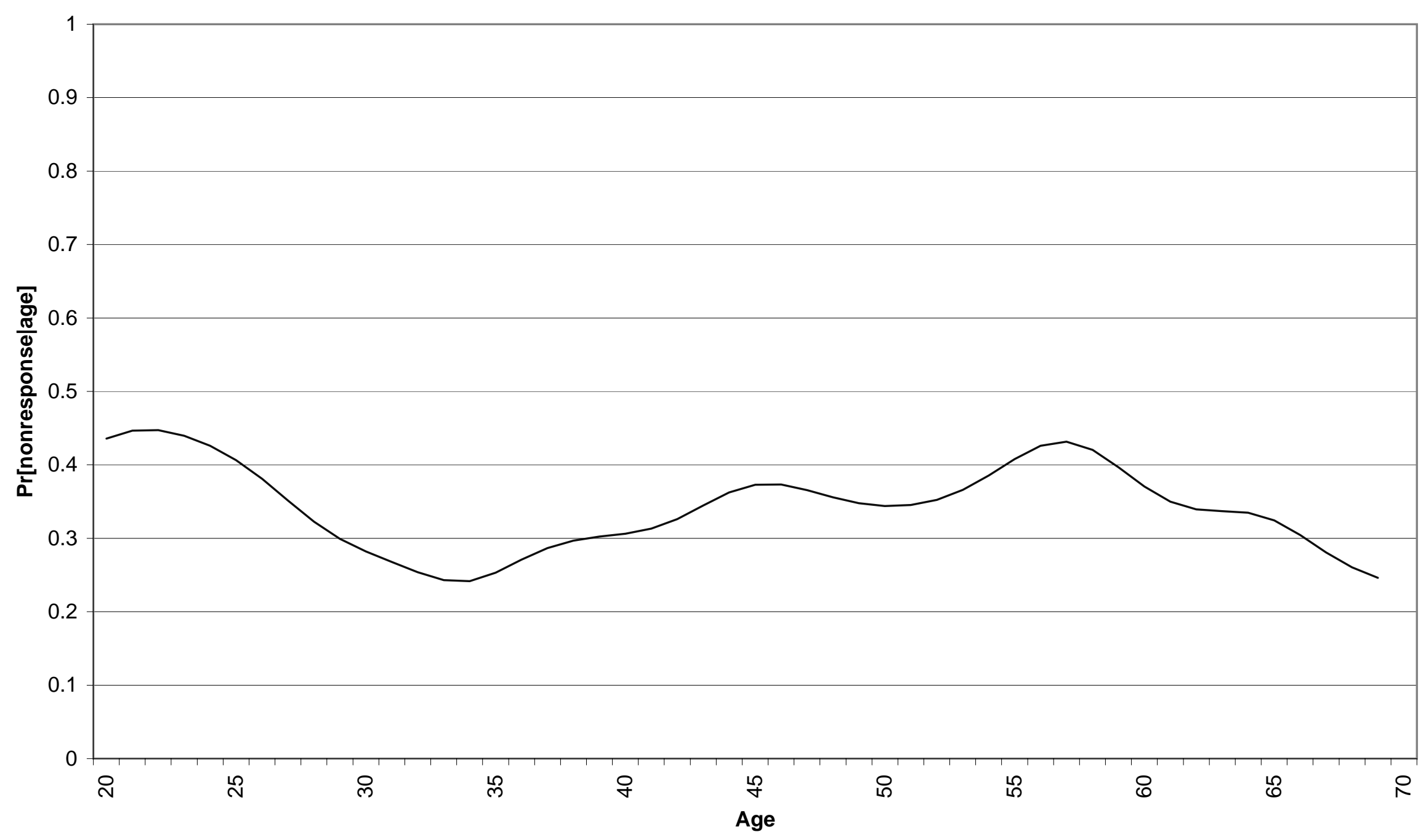


Figure 2. Quantiles of Probability of Receiving Social Security Benefits at Age 70, Conditional on Current Age

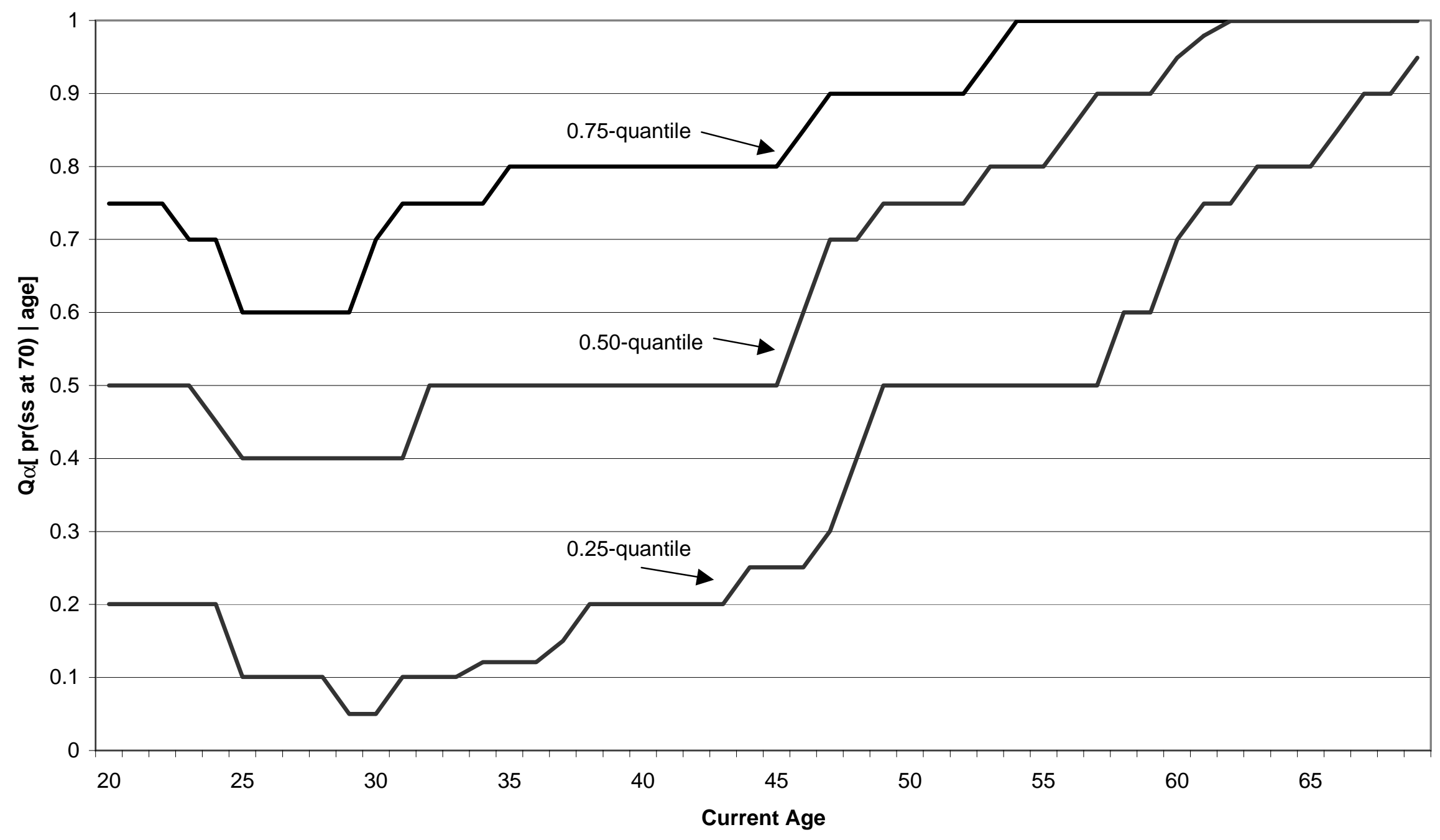


Figure 3. Probability of "Yes" Response to Dichotomous Social Security Eligibility Question: Health and Retirement Study (HRS) and Survey of Economic Expectations (SEE)

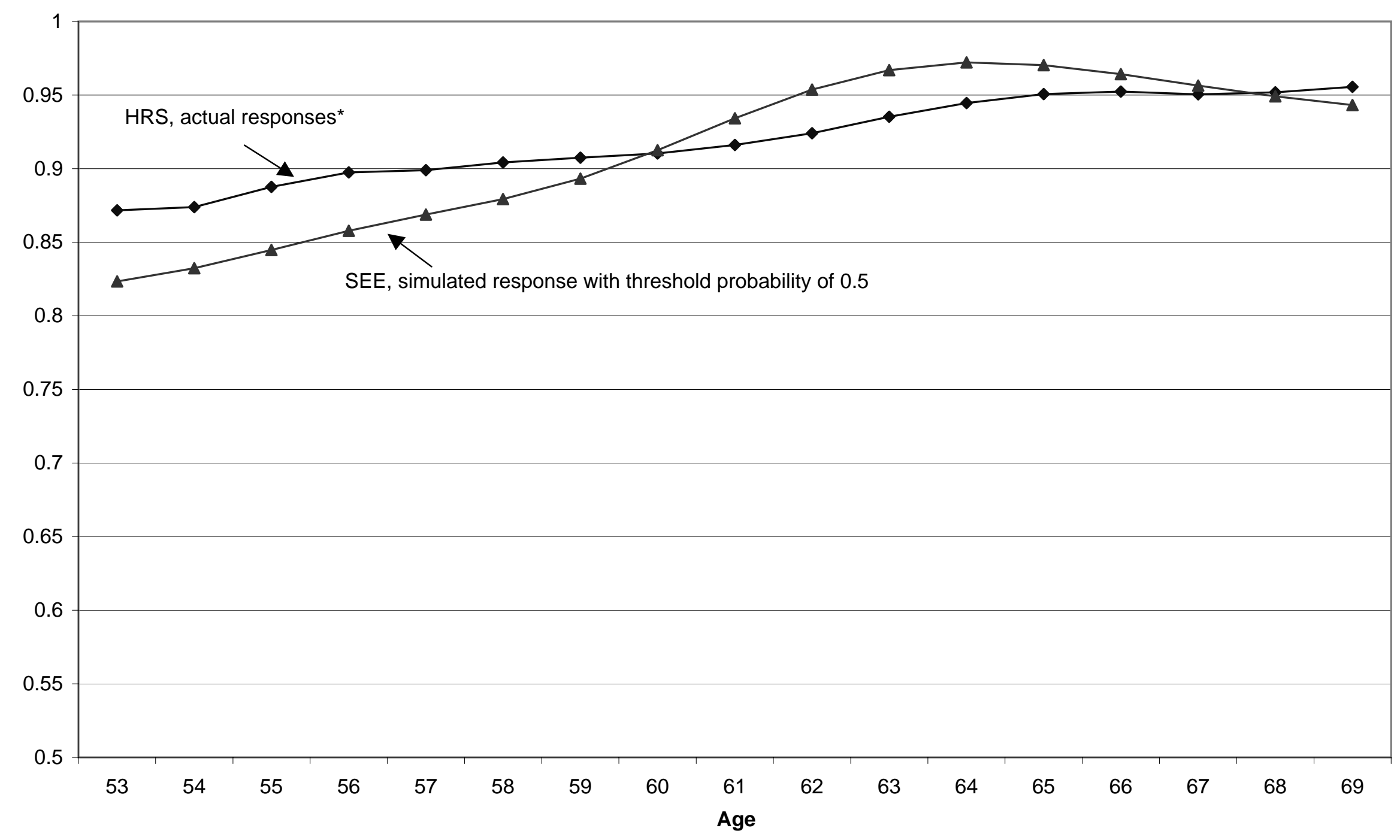

* HRS: "Financially-knowledgeable" respondents who report "yes," "no," or "don’t know." If currently receives benefits, "yes" is imputed. 
Figure 4. Quantiles of Subjective Median of Benefits at Age 70, Conditional on Current Age

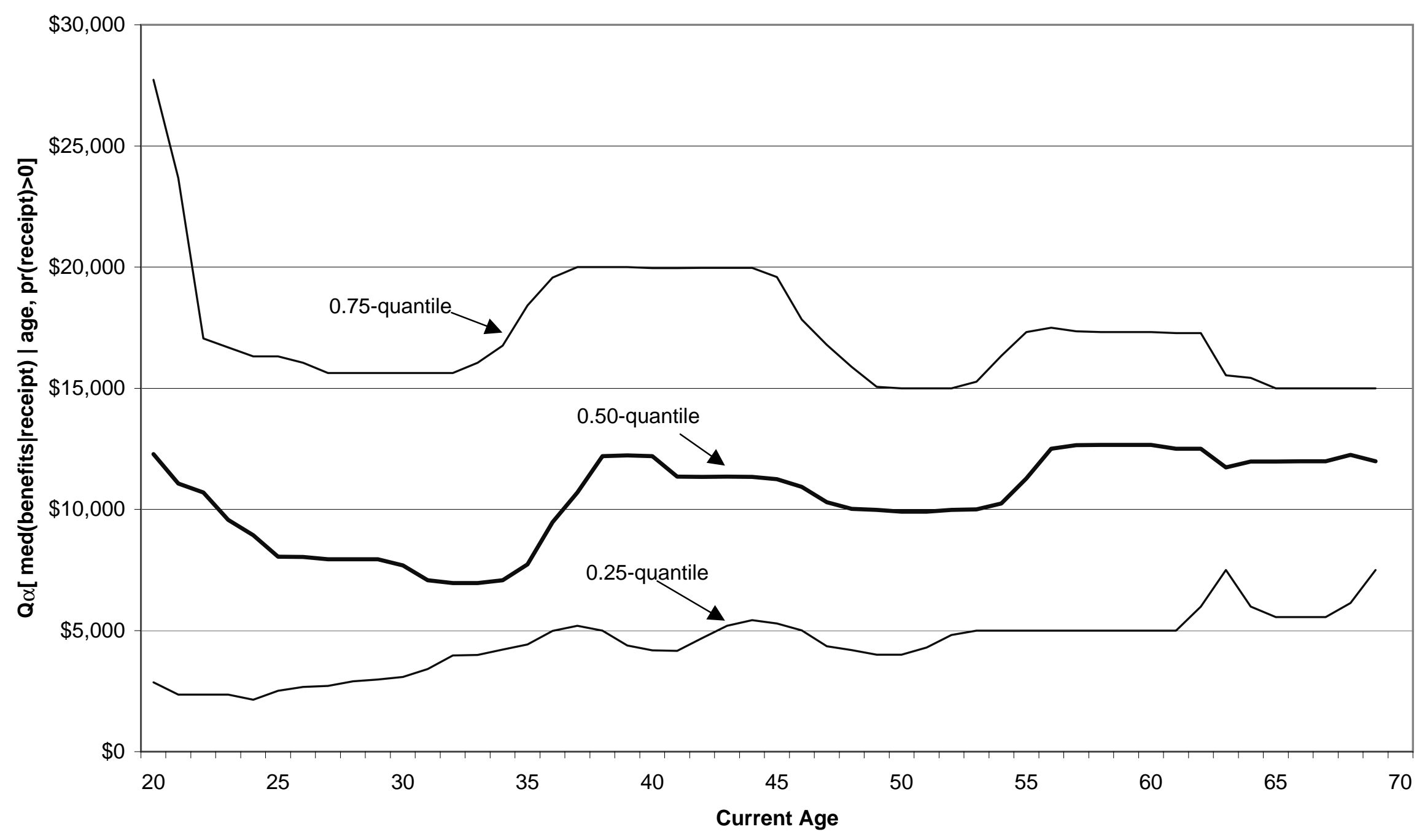


Figure 5. Quantiles of Subjective IQR of Benefits at Age 70,

Conditional on Current Age

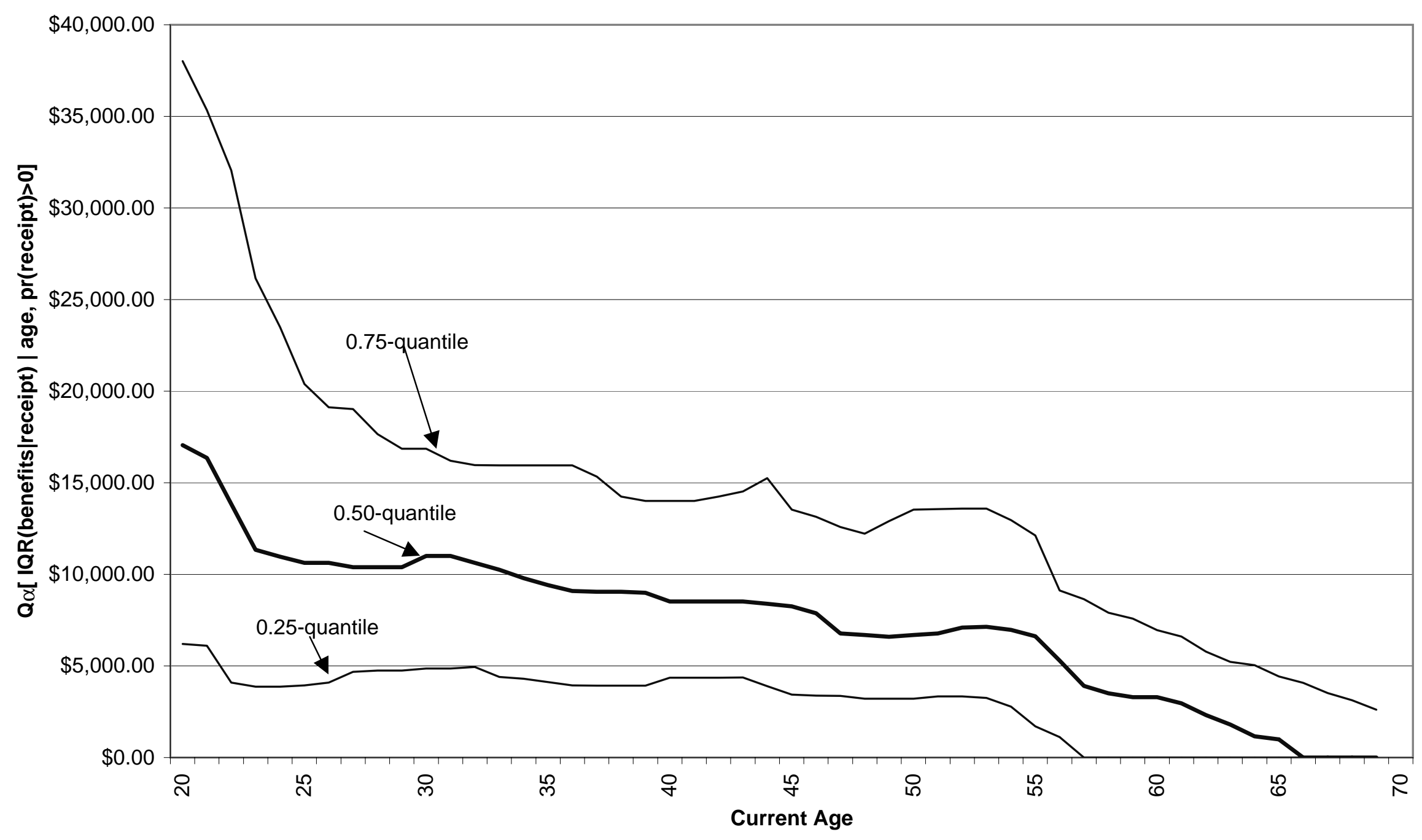


Figure 6. Expectations of Current Benefits: Subjective Median and "Best Estimate"

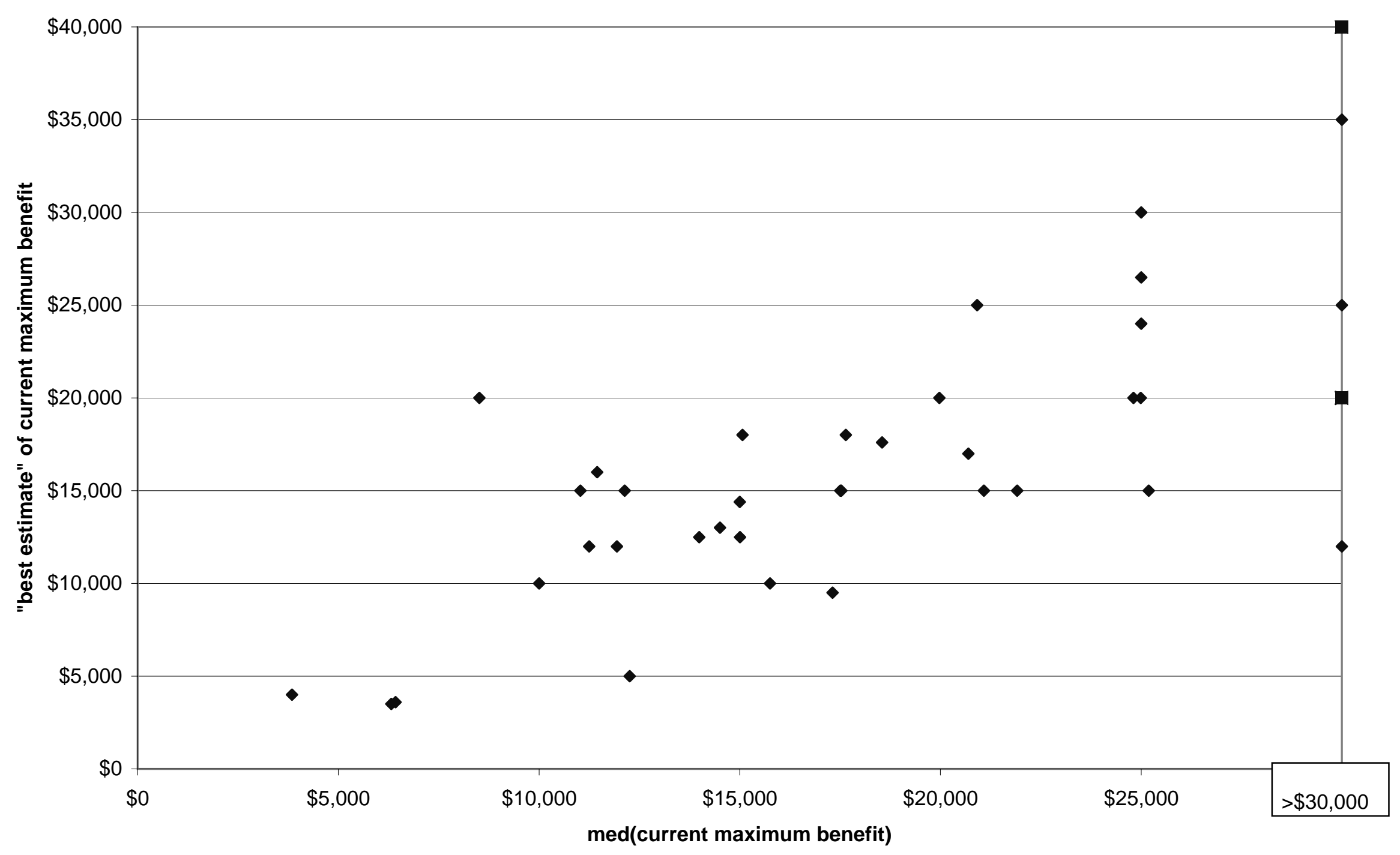


Figure 7. Expectations of Current Benefits: Subjective Median and Subjective IQR

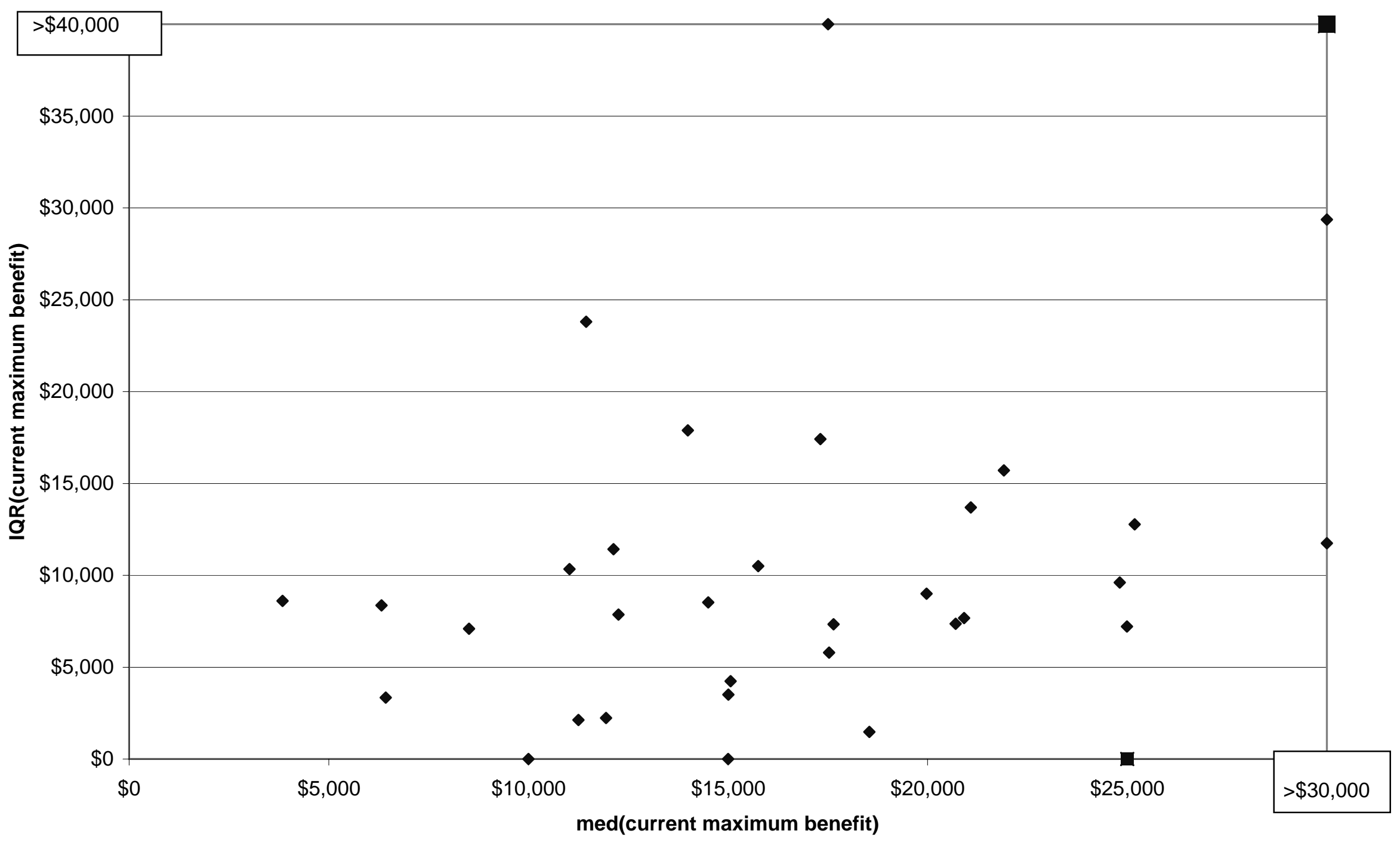

Source: 43 respondents to face-to-face-interviews. These interviews do not include branching algorithm used in the telephone interviews. Benefit thresholds in probability questions range from $\$ 5,000$ to $\$ 25,000$. 
Figure 8. Expectations of Current and Prospective Benefits: Subjective Medians

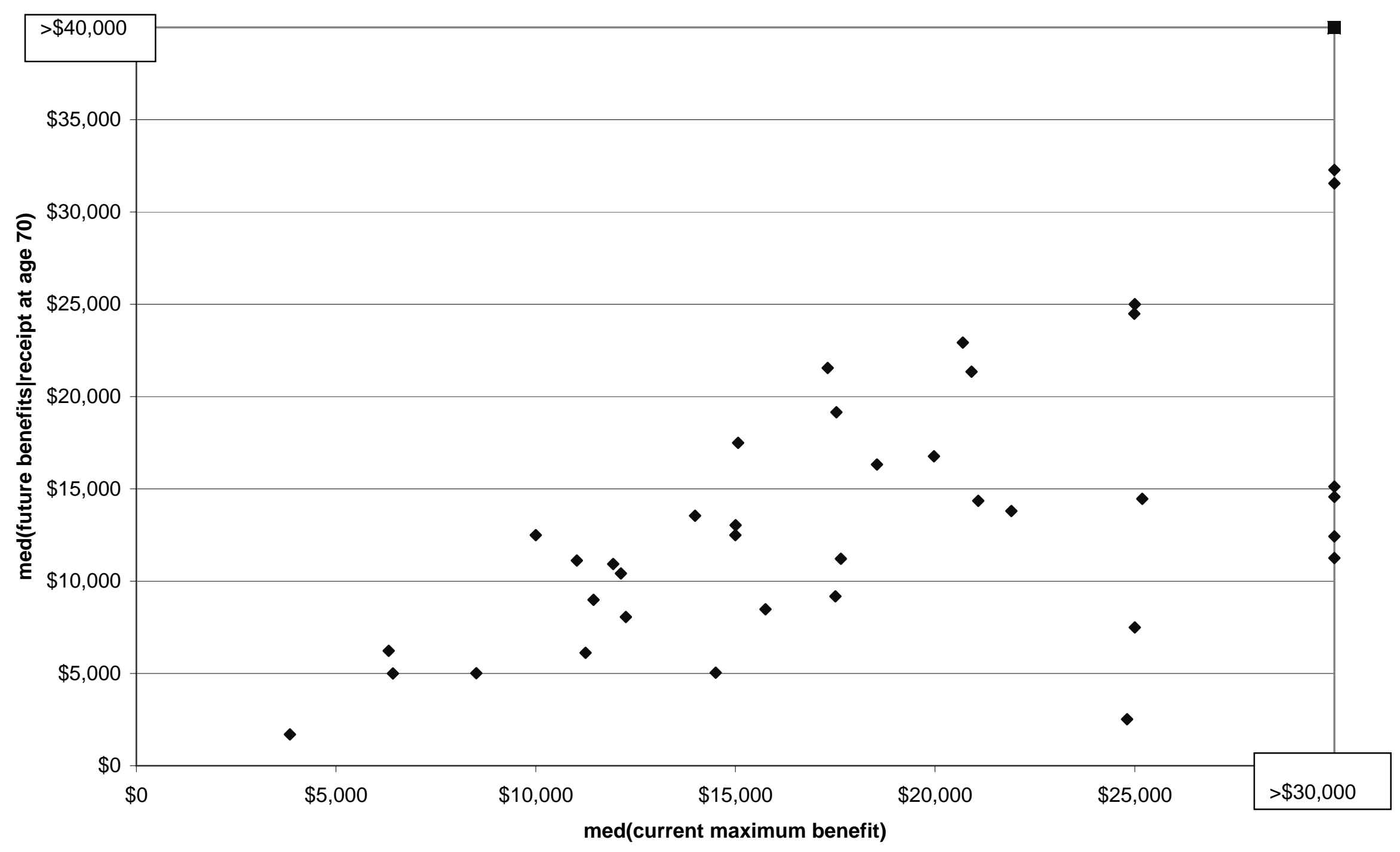


Figure 9. Expectations of Current and Prospective Benefits: Subjective IQRs

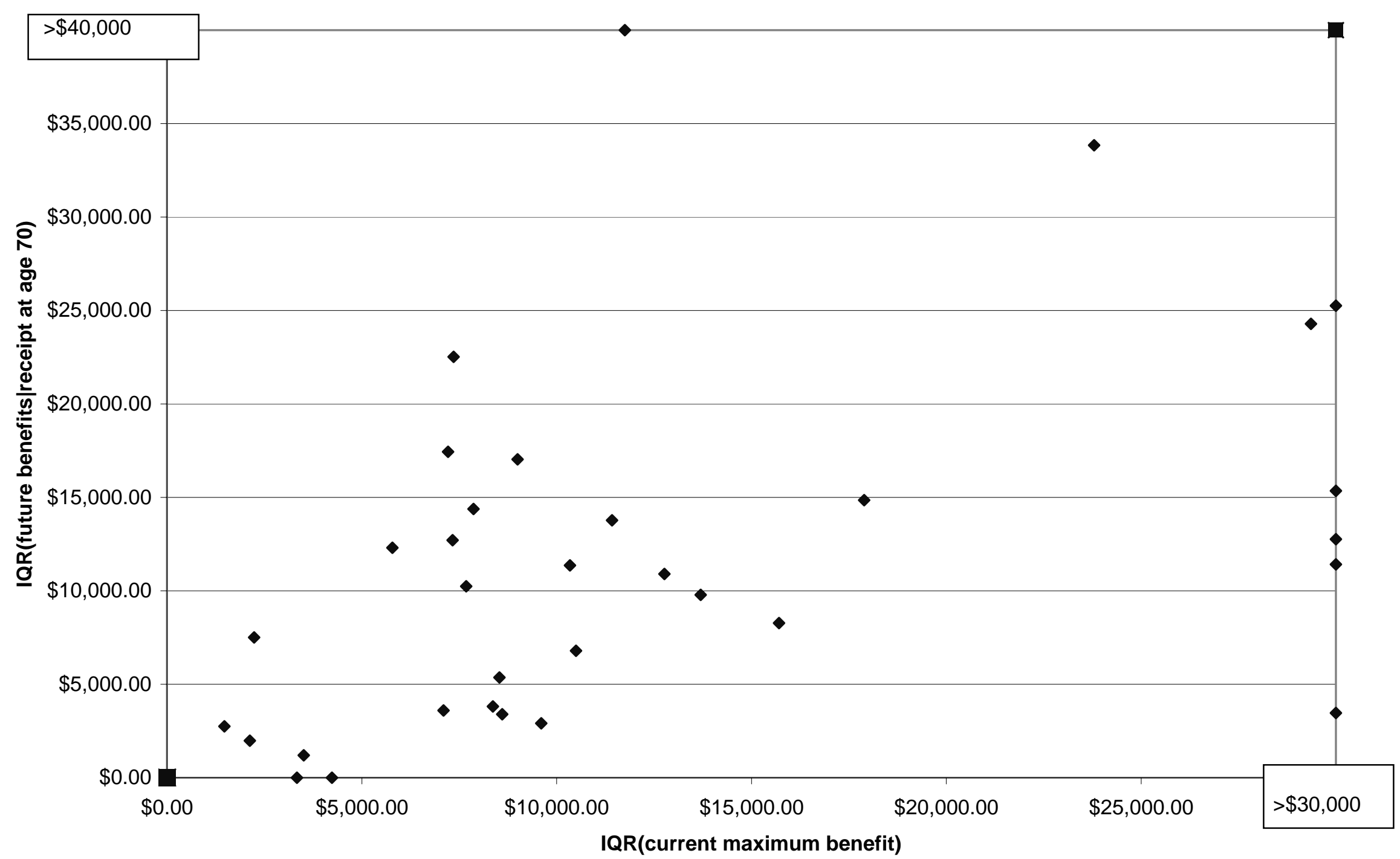


HRS 1998 - SECTION J: ASSETS AND INCOME — PAGE 548

FINAL VERSION 2 - 4/20/2001

J50b1. In what year did your [husband/wife/partner] start to receive Social Security benefits?

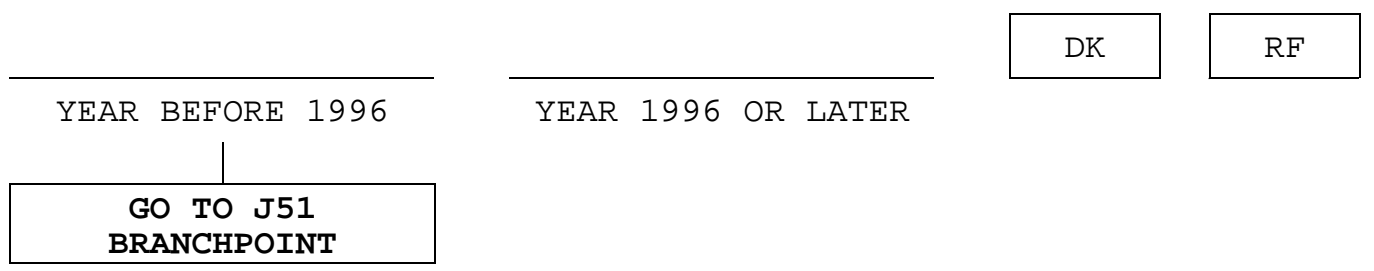

[IWER: IF 1996, 1997, OR 1998, ASK:]

(What month was that?)

J50b2 . MONTH :

\begin{tabular}{|c|c|c|c|c|}
\hline 01 . JAN & $02 . \mathrm{FEB}$ & 03. MAR & $04 . A P R$ & 05. MAY \\
\hline 06. JUN & 07. JUL & 08. AUG & 09. SEP & 10. OCT \\
\hline
\end{tabular}

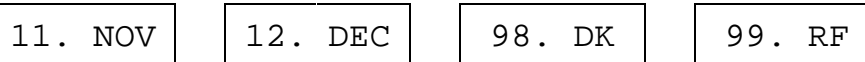

J51 BRANCHPOINT: IF R IS GETTING SOCIAL SECURITY BENEFITS NOW (J46=\{1 or 3$\}$ ), GO TO J55

J51. Do you expect to receive Social Security benefits at some time in the future?

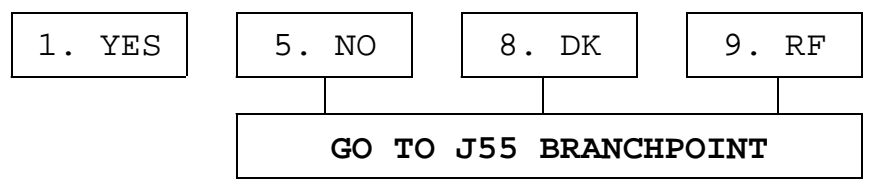

J52. At what age do you expect to start collecting these benefits?

\begin{tabular}{lll}
$\mathrm{DK}$ & $\mathrm{RF}$ \\
\hline $\mathrm{AGE}$
\end{tabular}

AGE 
HRS 1998 - SECTION J: ASSETS AND INCOME — PAGE 549

FINAL VERSION 2 - 4/20/2001

553. If you start collecting Social security benefits then, about how much do you expect the payments to be in today's dollars?

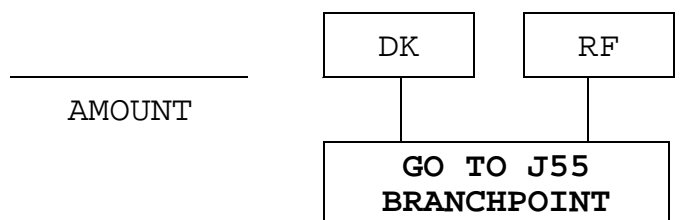

J53p. PER:

\section{WEEK}

\section{3. $E V B$}

6. YEAR

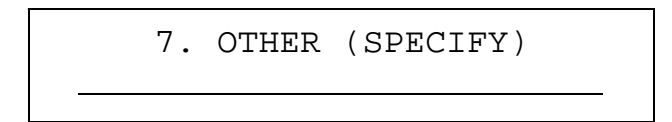

\section{4. $\mathrm{MONTH}$}

8. $\mathrm{DK}$
5. LUMP SUM

9. $\mathrm{RF}$

\section{J55 BRANCHPOINT:}

$$
\text { IF } \mathrm{R}^{\prime} \mathrm{S} \text { SPOUSE/PARTNER RECEIVES SOCIAL SECURITY BENEFITS }
$$
( J46 $=\{2$ or 3$\}$ ) or IF R IS NOT PART OF A MARRIED/PARTNERED COUPLE, GO TO J59

J55. Does your [husband/wife/partner] expect to receive Social Security benefits at some time in the future?

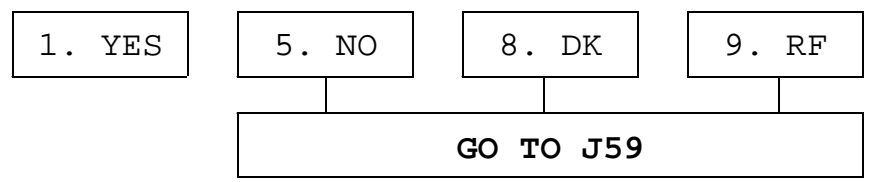

J56. At what age does [she/he] expect to start collecting these benefits?

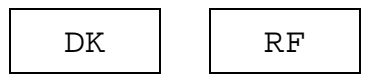


HRS 1998 - SECTION J: ASSETS AND INCOME — PAGE 550

FINAL VERSION 2 - 4/20/2001

557. If [she/he] starts collecting Social security benefits then, about how much do you expect the payments to be in today's dollars?

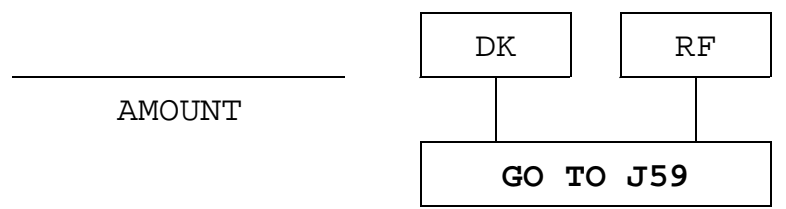

J57p. PER:

2. WEEK

6. YEAR
3. EVERY TWO WEEKS/BI-WEEKLY

7. OTHER (SPECIFY)
4. MONTH

8. DK
5. LUMP SUM

9. $\mathrm{RF}$

559. Did you (or your [husband/wife/partner]) receive any income last month from Supplemental Security Income, also called SSI?

DEFINITION: SSI IS A PROGRAM ADMINISTERED BY THE SOCIAL SECURITY ADMINISTRATION WHICH MAKES ASSISTANCE PAYMENTS TO LOW INCOME, BLIND, DISABLED, AND AGED PERSONS. A PERSON MAY BE RECEIVING EITHER OR BOTH SSI AND SOCIAL SECURITY CHECKS.

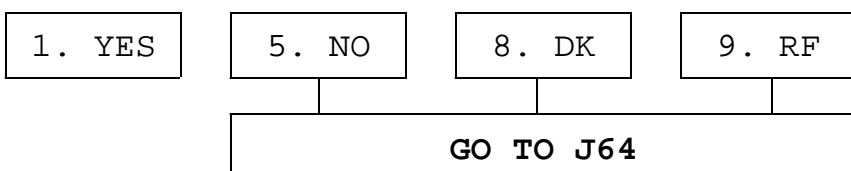

J60 BRANCHPOINT: IF R IS NOT PART OF A MARRIED/PARTNERED COUPLE, ASSIGN 1 FOR J60 AND GO TO J61

J60. Which one of you received income from SSI?

1. RESPONDENT
ONLY 2. SPOUSE/PARTNER
ONLY

\section{3. ВOTH}

9. $\mathrm{RF}$ 


\section{$\underline{\text { Response Rate to SEE Questions }}$}

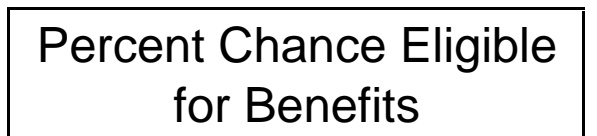

\begin{tabular}{c}
\hline $\begin{array}{c}\text { Lowest/Highest Amount } \\
\text { of Benefits }\end{array}$ \\
\hline
\end{tabular}

Percent Chance Benefits Exceed $\$ Y$

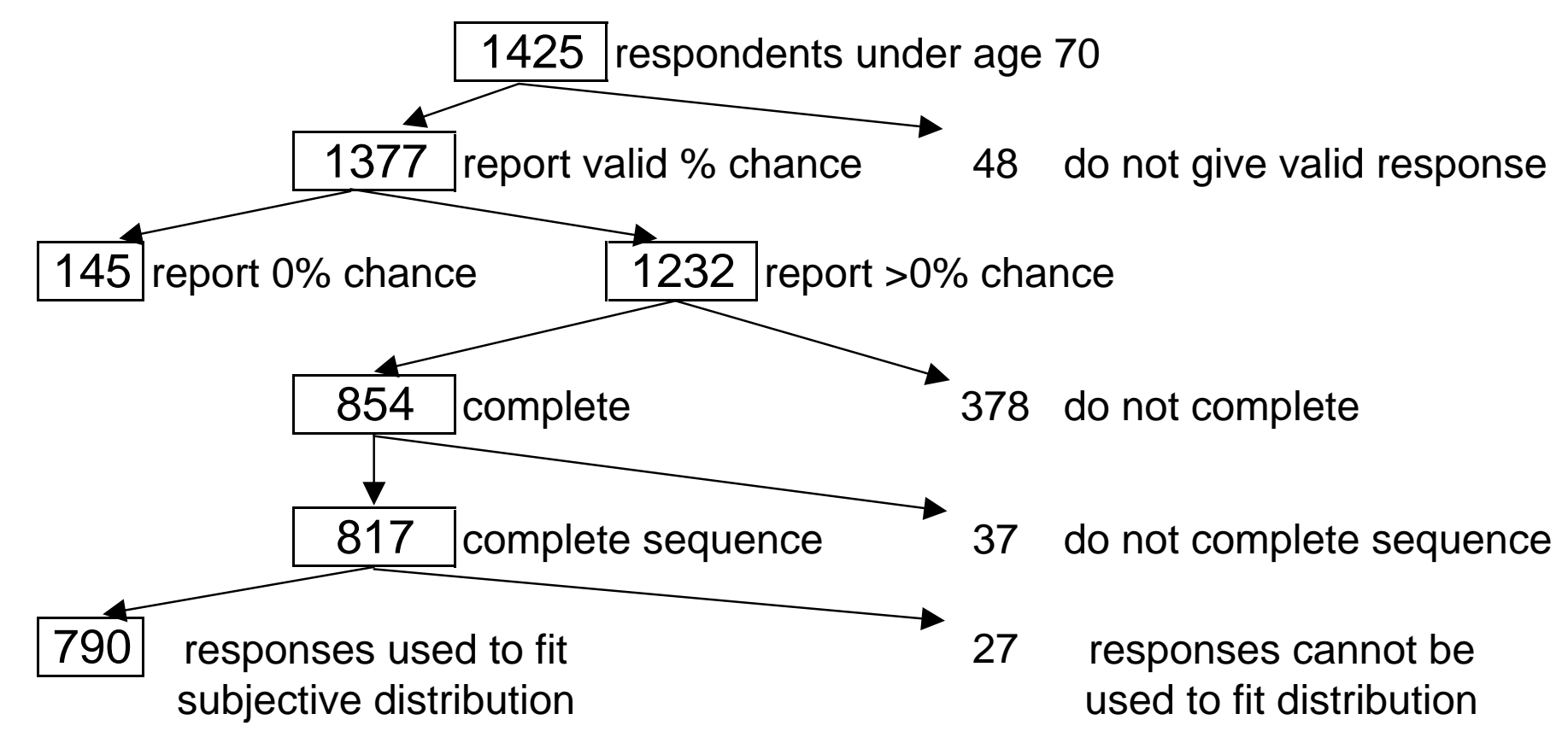

\section{Response Rate to HRS (2000) Questions}

Benefits

Expected Age When Start Collecting Benefits

Benefit Payments

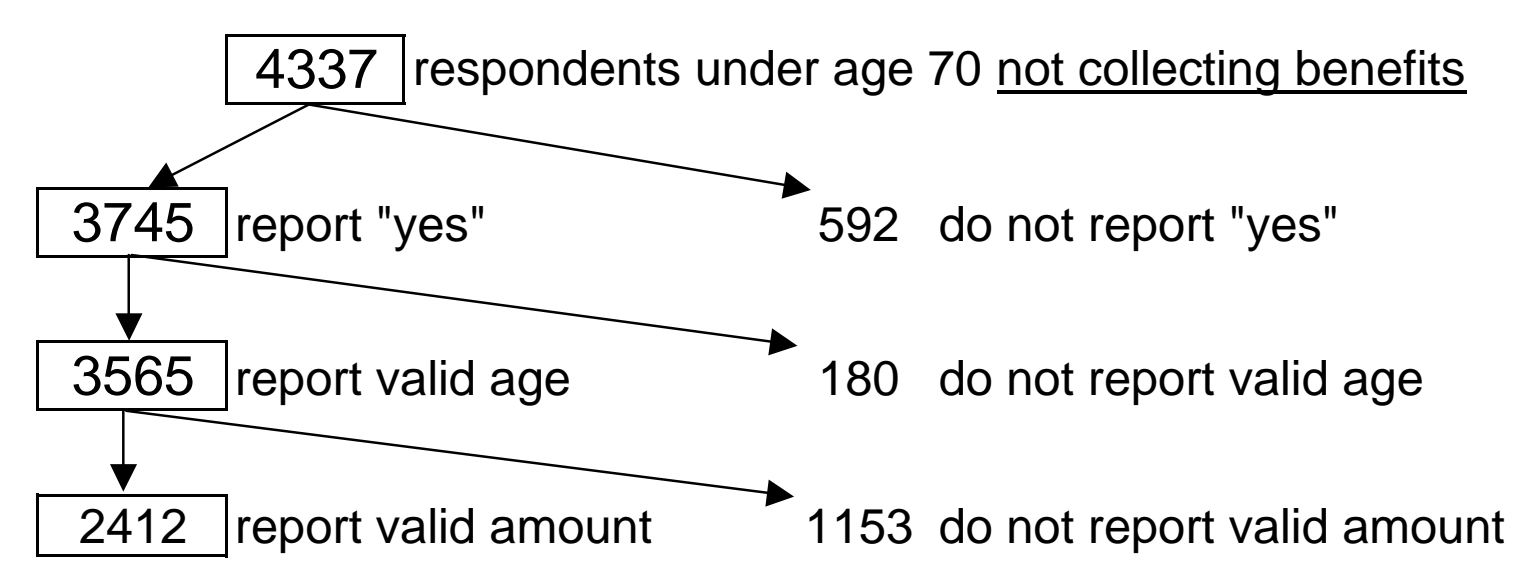


Table 1.B3.-OASDI benefits: Number and average monthly benefit in current-payment status for adult beneficiaries, by type of benefit, sex, and age, March 2001

\begin{tabular}{|c|c|c|c|c|c|c|c|c|}
\hline \multirow[b]{2}{*}{ Type of benefit and sex } & \multicolumn{4}{|c|}{ Number of beneficiaries (in thousands) } & \multicolumn{4}{|c|}{ Average monthly benefit } \\
\hline & Total & Under 62 & $62-64$ & 65 or older & Total & Under 62 & $62-64$ & 65 or older \\
\hline Total $^{1}$.. & 42,448 & 5,665 & 4,043 & 32,740 & $\$ 797.54$ & $\$ 718.82$ & $\$ 752.98$ & $\$ 816.67$ \\
\hline Retired workers & 28,628 & & 2,620 & 26,008 & 846.48 & & 776.61 & 853.51 \\
\hline Disabled workers. & 5,083 & 4,401 & 683 & & 787.37 & 776.30 & 858.75 & \\
\hline 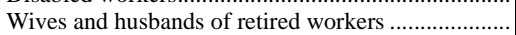 & 2,782 & 48 & 312 & 2,423 & 429.59 & 322.15 & 402.91 & 435.13 \\
\hline Wives and husbands of disabled workers ................... & 161 & 109 & 29 & 23 & 197.84 & 162.83 & 268.41 & 275.19 \\
\hline 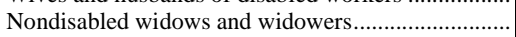 & 4,668 & 131 & 318 & 4,219 & 812.57 & 768.31 & 776.14 & 816.69 \\
\hline 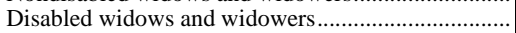 & 202 & 145 & 56 & $\ldots$ & 520.12 & 521.13 & 517.51 & \\
\hline Mothers and fathers & 189 & 183 & 5 & 1 & 587.91 & 586.28 & 643.35 & 589.43 \\
\hline 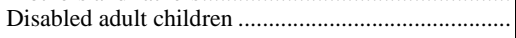 & 731 & 647 & 19 & 64 & 519.63 & 522.99 & 533.26 & 481.38 \\
\hline Men ${ }^{1}$ & 18,198 & 2,857 & 1,795 & 13,546 & 930.14 & 816.69 & 939.08 & 952.89 \\
\hline Retired workers & 14,839 & & 1,374 & 13,465 & 953.26 & & 925.01 & 956.14 \\
\hline 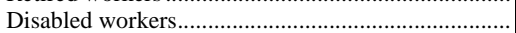 & 2,871 & 2,473 & 399 & $\ldots$ & 883.60 & 863.36 & $1,009.09$ & \\
\hline 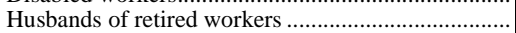 & 33 & (2) & 1 & 31 & 242.90 & (2) & 216.38 & 243.93 \\
\hline 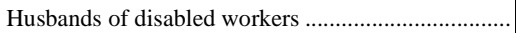 & 4 & 2 & $(2)$ & 1 & 155.94 & 125.36 & $(2)$ & 195.95 \\
\hline 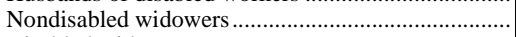 & 37 & 7 & 10 & 20 & 610.83 & 574.72 & 668.21 & 595.19 \\
\hline 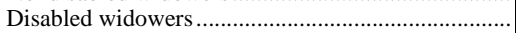 & 5 & 4 & 1 & $\ldots$ & 363.09 & 365.82 & 352.26 & $\ldots$ \\
\hline 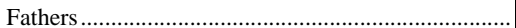 & 9 & 9 & (2) & (2) & 495.84 & 495.75 & (2) & (2) \\
\hline 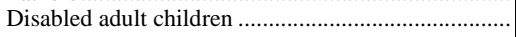 & 400 & 362 & 10 & 28 & 517.32 & 520.00 & 526.92 & 478.95 \\
\hline 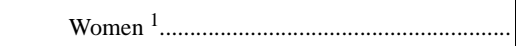 & 24,251 & 2,808 & 2,248 & 19,195 & 698.04 & 619.24 & 604.37 & 720.53 \\
\hline Retired workers & 13,790 & & 1,246 & 12,544 & 731.57 & & 612.99 & 743.35 \\
\hline 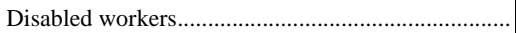 & 2,212 & 1,928 & 284 & & 662.48 & 664.65 & 647.73 & \\
\hline Wives of retired workers & 2,749 & 48 & 310 & 2,391 & 431.81 & 322.28 & 403.61 & 437.64 \\
\hline 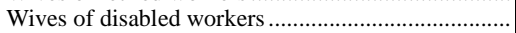 & 157 & 107 & 29 & 21 & 198.91 & 163.55 & 270.16 & 280.75 \\
\hline Nondisabled widows & 4,632 & 124 & 308 & 4,199 & 814.18 & 779.43 & 779.61 & 817.74 \\
\hline Disabled widows & 197 & 141 & 55 & $\ldots$ & 524.32 & 525.75 & 520.67 & \\
\hline 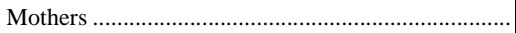 & 180 & 174 & 5 & 1 & 592.57 & 590.96 & 645.71 & 592.74 \\
\hline 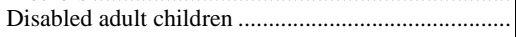 & 331 & 285 & 10 & 36 & 522.41 & 526.78 & 539.60 & 483.25 \\
\hline
\end{tabular}

${ }^{1}$ Includes parents and special age-72 beneficiaries. Excludes 97,768 student beneficiaries aged 18-19.

${ }^{2}$ Fewer than 500 beneficiaries. 